
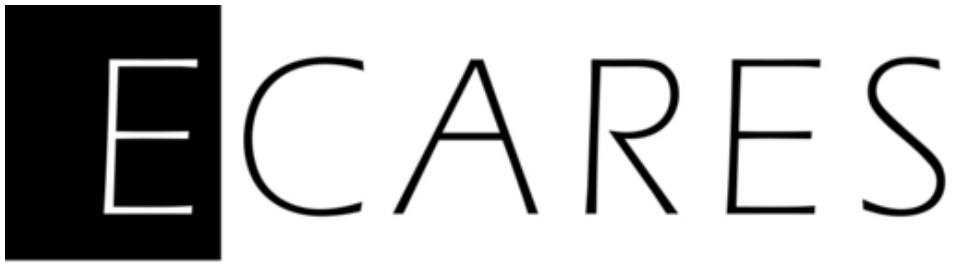

\title{
Identifying Financial Constraints from Production Data
}

\author{
Laurens Cherchye \\ Department of Economics, KU Leuven \\ Bram De Rock \\ ECARES, SBS-EM, Université libre de Bruxelles \\ Department of Economics, KU Leuven \\ Annalisa Ferrando \\ European Central Bank \\ Klaas Mulier \\ University Ghent, National Bank of Belgium \\ Marijn Verschelde \\ IESEG School of Management, Paris \\ Department of Economics, KU Leuven
}

November, 2018

ECARES working paper 2018-31

ECARES

ULB - CP 114/04

50, F.D. Roosevelt Ave., B-1050 Brussels BELGIUM

www.ecares.org 


\title{
Identifying Financial Constraints from Production
}

Data*

\author{
Laurens Cherchye ${ }^{\dagger} \quad$ Bram De Rock $^{\ddagger} \quad$ Annalisa Ferrando ${ }^{\S}$ \\ Klaas Mulier Marijn Verschelde"
}

November 5, 2018

\begin{abstract}
Farre-Mensa and Ljungqvist (2016, RFS) argue that the existing and widely used measures of financial constraints are inadequate and fail to measure financial constraints. We propose a new methodology to recover firm-year level financial constraints from firms' production behavior. In particular, we measure financial constraints as the profitability that firms forgo when binding constraints on input costs impede them from using the optimal level of inputs and technology. We validate our measure using a unique dataset combining firms' balance sheets from 2005 to 2015 in five Euro Area countries with survey information on firms' self-reported financial constraints, such as actual loan rejections or discouragement. Further, we show that our measure recovers the country-specific trends of financial constraints during the financial crisis and the sovereign debt crisis, and correlates only weakly with the three most popular indices of financial constraints.
\end{abstract}

${ }^{*}$ The authors would like to thank Nico Dewaelheyns, Angelos Theodorakopoulos, and Silvio Vismara for useful comments. Laurens Cherchye gratefully acknowledges the European Research Council (ERC) for his Consolidator Grant 614221. Bram De Rock gratefully acknowledges the FWO and FNRS for their support. The views expressed are solely those of the authors and do not necessarily represent the views of the European Central Bank or the National Bank of Belgium.

${ }^{\dagger}$ Katholieke Universiteit Leuven. e-mail: laurens.cherchye@kuleuven.be.

${ }^{\ddagger}$ ECARES, Université libre de Bruxelles and Katholieke Universiteit Leuven, e-mail: bderock@ulb.ac.be.

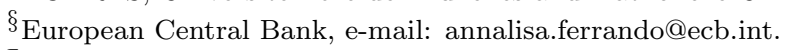

『Ghent University and National Bank of Belgium, e-mail: klaas.mulier@ugent.be.

"IÉSEG School of Management, LEM (UMR-CNRS 9221) and Katholieke Universiteit Leuven, e-mail: m.verschelde@ieseg.fr. 


\section{Introduction}

Financial constraints are often characterized in terms of the inelasticity of the supply of external finance, implying that financial constraints will impact firm decisions whenever internal financing is insufficient. Chodorow-Reich (2014) and Amiti and

Weinstein (2018), for instance, show that credit supply shocks -which essentially affect this elasticity of supply- explain at least 30 percent of aggregate employment and investment changes. Resolving financial constraints is therefore a major policy concern. However, for policy interventions to be timely and effective, it is crucial to dispose of a measure that adequately tracks the level and evolution of financial constraints.

Unfortunately, recent research by Farre-Mensa and Ljungqvist (2016) argues that the measures of financial constraints that exist up to date in the literature fail to adequately recover financial constraints. These measures, including popular indices developed by Kaplan and Zingales (1997), Whited and Wu (2006), and Hadlock and Pierce (2010), have in common that they are proxy variable approaches that try to measure financial constraints by a combination of observable characteristics. However, in practice, many unobservable characteristics (e.g. management quality, customer dependence, investment opportunities, banks' lending standards, etc.) also play an important role.

Our new measure. In this paper, we take an alternative approach by recovering financial constraints from the actual optimizing behavior of profit maximizing firms. We build our identification strategy on the findings that for homogeneous sets of firms, firm growth constraints have predominantly a financial nature (see e.g. Beck 
et al. (2005)). In our model, binding input cost constraints reflect a highly inelastic supply of external finance within narrowly defined sets of firms. A distinguishing feature of our methodology, when compared to investment-based approaches, is that we consider constraints on the total cost of all observed inputs (and not only tangible fixed assets) and explicitly take into account unobserved differences in productivity across firms. In particular, we recover financial constraints as the firms' foregone profitability due to binding input cost constraints that prohibit them from using the optimal level of inputs given their productivity.

Our framework is broadly applicable, as it solely requires production data. ${ }^{1}$ To demonstrate this, we measure firm-year level financial constraints for more than 120,000 manufacturing firms in five Euro Area countries (Belgium, Germany, France, Italy, and Spain). We use detailed balance sheet and profit \& loss account information from Orbis Europe and have information from 2005 to 2015, totaling nearly 600,000 observations. We match this balance sheet information with the responses of firms that participated in the Survey on Access to Finance of Enterprises (SAFE) conducted by the European Central Bank and the European Commission. The SAFE database includes information on whether firms faced rejections on actual applications for external financing, whether firms were discouraged to apply for external financing, or whether they had no need at all for external financing. ${ }^{2}$

Empirical validation. We perform a number of analyses to shed light on the informational content and usefulness of our new financial constraints measure. First

1 Production data has the advantage that is more readily available than financial data, especially for smaller and unlisted firms, and more frequently available in a common format for different countries and years than survey data.

2 While the survey data is property of the ECB, we will make our firm-year specific financial constraints estimates and code publicly available after publication. 
of all, we show how our measures relates to observed differences across firms and the impact of the financial crisis. When looking across firms, we obtain that our financial constraints measure correlates positively and significantly with the firms' difficulty to access external finance. This holds for firms that recently had a rejected application for bank loans or that were discouraged to apply, despite their need. We find this for bank loans, but also for other sources of external finance such as, credit lines, trade credit, or equity. These results hold even after controlling for a wide battery of observable characteristics known to be important for access to external finance. This indicates that our measure captures more information on financial constraints than merely the characteristics observable to the econometrician.

When looking over time, our measure indicates that, on average, financial constraints declined from 2005 to 2007 and skyrocketed in 2008 and 2009 after the onset of the global financial crisis. After a small decline in 2010, our measure shows that financial constraints increased further during the sovereign debt crisis to a maximum in 2011 and 2012, after which our measure reveals a downward trend in financial constraints. Decomposing this information down to the country-level, we find that the global financial crisis, and especially the sovereign debt crisis, exacerbated financial constraints in Spain and Italy, compared to Belgium, Germany and France. All this empirical evidence validates our new measure by showing that it picks up the expected patterns across firms and time.

Next, we did two additional exercises to further analyze the adequacy of our measure. First, we try to falsify our measure and relate it to a number of non-financial constraints that firms face, such as lack of product demand, regulation, fierce competition, etc.. We find that our measure does not pick up any of these other obstacles that firms might face. Second, we observe that firms which our measure identifies as 
being financially constrained do indeed show behavior that is consistent with being financially constrained. That is, we find that these firms invest significantly less in tangible fixed assets, are constrained in their labor choice, rely more intensively on credit from suppliers, and grant less credit to customers. All this seems to indicate that that our measure is indeed able to isolate the firms' financial constraints.

Finally, we compare our measure of financial constraints with the three most popular and widely used indices in the literature, that is, the Kaplan-Zingales (KZ), Whited$\mathrm{Wu}(\mathrm{WW})$ and Hadlock-Pierce (HP) indices. The correlation between our measure and the KZ-index is less than 6 percent. The correlation with the WW-index is 23 percent and with the HP-index 16 percent. Although we are aware that a low correlation does not prove the adequacy of our measure as a measure of financial constraints, a (very) high correlation would likely indicate that our measure has the same flaws as the existing measures which have been pointed out by Farre-Mensa and Ljungqvist (2016).

Related literature. Our paper contributes to the extant literature on financial constraints. One of the earliest approaches to measure indirectly financial constraints was to classify firms according to a characteristic based on information asymmetry (e.g. size, credit rating, or industrial group affiliation) or based on revealed financing needs (e.g. dividend payout). The virtue of these measures was demonstrated by the higher investment-cash flow sensitivity of firms classified as constrained (see for instance Fazzari et al. (1988); Hoshi et al. (1991) and Carpenter et al. (1994, 1998)). The validity of this approach was later heavily criticized, starting by Kaplan and Zingales (1997) who built a text-based measure of financial constraints derived from the CEO's financial statement that accompanies the annual income statement of 49 
quoted firms, known as the KZ-index (Kaplan and Zingales, 1997; Lamont et al., 2001). Later, Whited and Wu (2006) constructed an index (WW-index) of financial constraints that is derived from an economic investment model. Hadlock and Pierce (2010) and Hoberg and Maksimovic (2014) have studied the content of these indices using larger and longer samples. Overall, their results suggest that most components of the KZ-index and WW-index do not (or no longer) relate to financial constraints, leading Hadlock and Pierce (2010) to propose an index based solely on size and age (HP-index).

Recently, Farre-Mensa and Ljungqvist (2016) came to the conclusion that none of the above discussed proxy variable approaches accurately measure financial constraints. By proposing a production behavior based methodology as full-fledged alternative for recovering financial constraints, we provide an accurate picture of financial constraints. We show that our methodology is not only a counterfactual framework without a priori parametric assumptions on the production process of firms, but also provides explanatory power beyond existing indicators of financial constraints

Outline. The remainder of the text is structured as follows. In Section 2, we propose the methodology to recover financial constraints from firms' production behavior, while correcting for unobserved heterogeneity in productivity (and the implied simultaneity issue). In Section 3, we describe the data and discuss the empirical set-up. In Section 4, we validate our advocated methodology and in Section 5 we conclude. 


\section{Methodology}

Our strategy to recover financial constraints is based on the actual production behavior of profit maximizing firms and thus requires production function identification. Seminal work of Marschak and Andrews (1944) and Olley and Pakes (1996) shows that input choices of firms can depend on productivity, implying a simultaneity issue when this dependency is disregarded. We follow Cherchye et al. (2018) by considering productivity as latent input costs that may be chosen endogenously and usually have a technological nature (e.g., intangibles). When information on input costs (including latent inputs) is complete, there is no unobserved heterogeneity in productivity. Conversely, incomplete information on input costs implies unobserved heterogeneity that may cause an endogeneity issue. In Section 2.1., we show how to recover financial constraints from production data when abstracting from unobserved heterogeneity in productivity. In Section 2.2., we discuss how the framework of Cherchye et al. (2018), which focused on cost minimizing firms, can be extended to allow for nonparametric identification of unobserved productivity of profit maximizing firms that may face financial constraints. In Section 2.3., we discuss the practical implementation of our proposed measure of foregone profitability due to financial constraints.

\subsection{Recovering financial constraints from production behav- ior}

Following the original ideas of Shephard (1974), McFadden (1978), Lee and Chambers (1986) and Färe et al. (1990) ${ }^{3}$, we assume financial constraints as unobserved

\footnotetext{
${ }^{3}$ See Blancard et al. (2006) for an extension of this methodology to differ between short- and long-run credit constraints.
} 
constraints on profit maximization. We identify financial constraints from the observed firms' production behavior, using the assumption that these constraints are potentially binding. Loosening these binding constraints is thus expected to raise firm profits.

Two preliminary remarks are in order. First, we follow the abovementioned papers by assuming that financial constraints are exogenous to the behavior of the firms. This also makes that these constraints do not depend on the firms' unobserved productivity levels. Next, we will model the firm's optimization problem as static rather than dynamic. Importantly, however, under intertemporal separability of the firm's intertemporal objective function, static optimization is a necessary condition for dynamic optimization. ${ }^{4}$

No heterogeneity in productivity. To sketch the basic intuition of our approach, we first assume a setting without unobserved heterogeneity in productivity across firm observations. That is, we assume that we observe all the inputs (and their corresponding costs). Our analysis starts from a dataset $S=\left\{\mathbf{W}_{i}, \mathbf{X}_{i}, P_{i}, Q_{i}\right\}_{i \in N}$, with $\mathbf{W}_{i} \in \mathbb{R}_{++}^{M}$ the observed input prices, $\mathbf{X}_{i} \in \mathbb{R}_{+}^{M}$ the observed input levels, $P_{i} \in \mathbb{R}_{++}$the observed output price, and $Q_{i} \in \mathbb{R}_{++}$the observed output level for a set of $N$ firm observations.

Figure 1 shows a textbook example of profit maximizing firm behavior (with a single input, i.e. $M=1$ ). It illustrates how to recover financial constraints from production data under the maintained assumption of profit maximization. All firms operate under the same technology, which is represented by the production function $Q=$

\footnotetext{
${ }^{4}$ In the static optimization problem, intertemporal interdependence of input and output decisions can then be accounted for by suitably pricing inputs and outputs over the consecutive time periods.
} 
$F(\mathbf{X})$. Next, we assume that firm $j$ achieves a maximal profit when facing the prices $P_{i}$ and $\mathbf{W}_{i}$, which implies that the hyperplane $\Pi_{j}=P_{i} Q-\mathbf{W}_{i} \mathbf{X}$ is tangent to the function $F$ in the point $\left(\mathbf{X}_{j}, Q_{j}\right)$. If firm $i$ faces the same prices, then the output $Q_{i}$ and inputs $\mathbf{X}_{i}$ do not yield maximum profit, i.e. the hyperplane $\Pi_{i}=P_{i} Q-\mathbf{W}_{i} \mathbf{X}$ intersects the function $F$ in the point $\left(\mathbf{X}_{i}, Q_{i}\right)$. In our approach, we take it that firm $i$ reveals its financial constraint by its suboptimal input choice. In particular, as any choice of $\mathbf{X}$ between $\mathbf{X}_{i}$ and $\mathbf{X}_{j}$ implies more profit than $\Pi_{i}$, we identify that firm $i$ 's input cost is constrained by the upper bound $C^{*}=\mathbf{W}_{i} \mathbf{X}_{i}$.

\section{FIGURE 1 HERE}

Heterogeneity in productivity. In practice, the empirical analysis of profit maximizing firm behavior is often complicated by unobserved heterogeneity in productivity (i.e., differences in intangible assets, R\&D expenses, etc.). As we will explain in more detail below, we follow Cherchye et al. (2018) by modeling unobserved productivity variation in terms of latent input $\Omega$. The dataset $S$ does not contain any information on this productivity term $\Omega$, but productivity does affect the firms' observed output and input choices. The production technology depends on both observed inputs $\mathbf{X}$ and the unobserved input $\Omega$, which implies $Q=F(\mathbf{X}, \Omega)$. It is important to effectively account for the presence of heterogeneity in productivity in order to achieve an adequate empirical assessment of profit maximizing firm behavior.

Figure 2 extends our previous example and illustrates the relevance of explicitly accounting for heterogeneity in productivity. We assume that the firms $i$ and $j$ are characterized by different levels of productivity, $\Omega_{i}$ and $\Omega_{j}$. In this case, the curves through the points $i$ and $j$ represent the corresponding projections of the production 
function $F(\mathbf{X}, \Omega)$. Clearly, the two firms $i$ and $j$ are characterized by different production possibilities in terms of the observed output $Q$ and input $\mathbf{X}$, and our analysis of Figure 1 is no longer valid. In particular, we find that firm $i$ 's foregone profit loss due to financial constraints is lower when accounting for differences in latent input. Generally, erroneously omitting latent input can bias the estimated profit losses due to financial constraints in any unpredictable way.

Moreover, foregone profit estimates that omit latent inputs are subject to a simultaneity issue originating from the dependency of observed input choice on unobserved technological features (see Marschak and Andrews (1944) and Olley and Pakes (1996)). The literature on the estimation and identification of production functions has paid considerable attention to developing techniques that address this dependency problem. Notable examples include Olley and Pakes (1996), Levinsohn and Petrin (2003), Wooldridge (2009) and, more recently, Ackerberg et al. (2015) and Gandhi et al. (2016). These existing approaches require a (semi)parametric specification of the production technology, implying a potential functional form misspecification bias. The approach of Cherchye et al. (2018) that we use in the current paper avoids imposing parametric structure on the technological production possibilities. It allows us to identify financial constraints in terms of foregone profit, by explicitly including latent input, which is endogenous to observed input choices, into our profit maximization analysis.

FIGURE 2 HERE

\subsection{Nonparametric identification of productivity}

Cherchye et al. (2018) proposed a full-fledged nonparametric method to identify 
production functions of cost minimizing firms that are characterized by unobserved heterogeneity in productivity. ${ }^{5}$ The method avoids functional specification bias by not imposing any nonverifiable parametric structure on the production technology. It also avoids the simultaneity bias in a natural way by including the unobserved aspects of production (i.e. unobserved inputs) directly in the optimization problem. In this paper, we extend this framework of Cherchye et al. (2018) to the case of constrained profit maximization. ${ }^{6}$ This will allow us to nonparametrically identify financial constraints from the observed production behavior.

Structural model. As in Cherchye et al. (2018), we assume a production function $Q=F(\mathbf{X}, \Omega)$, i.e. we consider latent input $\Omega$ as an endogenous choice variable for the firm. The firm's problem is to maximize profits by optimally choosing its output and inputs, which comprise both observed inputs and latent input. Given our specific research question, we assume profit maximization subject to financial constraints pertaining to the observed inputs. Particularly, we assume that the observed input cost cannot exceed some predefined level $C{ }^{7}$ This gives the optimization problem

$$
(O P) \quad \max _{\mathbf{X}, \Omega} P F(\mathbf{X}, \Omega)-\mathbf{W X}-\Omega \text { s.t. } \mathbf{W X} \leq C
$$

${ }^{5}$ Cherchye et al. (2018) extend the micro-economic literature on nonparametric production analysis of Afriat (1972); Hanoch and Rothschild (1972); Diewert and Parkan (1983); Varian (1984) by introducing unobserved productivity that is endogenous to observed input choices.

${ }^{6}$ Our framework is somewhat less general, since for our operationalization we need to assume the same latent input price across observations.

7 We remark that our particular empirical set-up makes that we cannot explicitly model financial constraints related to the unobserved inputs. As we have no information on the latent input, it is empirically meaningless to impose restrictions on the associated costs. Of course, in reality there may well be financial constraints related to these unobserved variables. In such cases, our approach implicitly assumes that these constraints are sufficiently correlated with those on the observed inputs. 
Checking consistency with this optimization problem requires identifying the unknown production technology $F$ of the firm, the latent input $\Omega$ and the budget constraint $C$. Throughout, we will assume that all input-output combinations with observed cost below $C$ (for the given prices $\mathbf{W}$ ) are feasible under the prevailing financial constraints.

In Appendix A, we present the testable implications that our data set $S$ needs to satisfy to be consistent with the above structural model. We also show that this can be easily operationalized in noisy settings by means of a simple linear program. This procedure allows us to compute the latent inputs $\Omega$.

Financial constraints as foregone profitability. To facilitate comparison across firms, we use profitability (i.e., revenues over costs) as our metric of firms' profits. Focusing on profitability allows us to naturally scale profit differences, but we can straightforwardly replace this by alternative profit measures. ${ }^{8}$

Assume that a firm observation $j$ achieves a higher profitability than the firm observation $i$ at the prices $\left(\mathbf{W}_{i}, P_{i}\right)$ that apply to $i$. When computing the associated foregone profitability due to financial constraints - our indicator of financial constraints $\mathrm{FC}$ - of firm $i$ relative to firm $j$, it is important to effectively account for the possibility of unobserved heterogeneity in productivity. Particularly, under the assumption of no unobserved heterogeneity (i.e. complete information on the input

\footnotetext{
${ }^{8}$ Generally, analyzing profitability (i.e., revenues over costs) is exactly equivalent to analyzing profit (i.e., revenues minus costs) only when the production function is characterized by constantreturns-to-scale (CRS). In our empirical application, we consider five firm size groups within narrowly defined industries and, therefore, we may reasonably expect that profitability measures provide adequate information on the latent constraints on profit maximization. Stated differently, for our application, we assume a CRS assumption "locally", implying that it only has to hold for the given firm size group.
} 
costs), our financial constraint measure is defined as

$$
F C_{i}^{* *}=\frac{P_{i} Q_{j}}{\mathbf{W}_{i} \mathbf{X}_{j}}-\frac{P_{i} Q_{i}}{\mathbf{W}_{i} \mathbf{X}_{i}}
$$

By contrast, when inputs are only partially observed, we can account for heterogeneity in productivity by explicitly including latent input in the analysis. This obtains the alternative financial constraint measure

$$
F C_{i}^{*}=\frac{P_{i} Q_{j}}{\mathbf{W}_{i} \mathbf{X}_{j}+\Omega_{j}}-\frac{P_{i} Q_{i}}{\mathbf{W}_{i} \mathbf{X}_{i}+\Omega_{i}}
$$

Following our discussion in Section 2.1, there is no reason to suspect that $F C_{i}^{* *}$ equals $F C_{i}^{*}$, resulting in an omitted variable bias when unobserved input costs are not acknowledged for. In our practical application, we can compute the measure $F C_{i}^{*}$ by using our estimates of latent input.

Measuring financial constraints. Relaxing financial constraints opens the door for production possibilities that go together with higher profitability. To empirically measure the foregone profitability due to prevailing financial constraints, we compare the actual profitability with a measure of achievable profitability under less stringent financial constraints.

For each firm $i$, we use as our measure of achievable profitability the average profitability (evaluated at the given prices $\left(\mathbf{W}_{i}, P_{i}\right)$ ) defined over all firm observations with more costly inputs than firm $i$. This represents the expected profitability when loosening firm $i$ 's financial constraints and provides an intuitive measure of foregone profit due to financial constraints. Other summary statistics, such as the median, maximum or some other quantile of the profitability distribution, can of course easily 
be used as well.

We specify the following measure of financial constraints:

$$
\begin{gathered}
F C_{i}=\max \left(0, \text { Average }_{j \in T_{i}^{\text {beyond }}}\left(\frac{P_{i} Q_{j}}{\mathbf{W}_{i} \mathbf{X}_{j}+\Omega_{j}}\right)-\frac{P_{i} Q_{i}}{\mathbf{W}_{i} \mathbf{X}_{i}+\Omega_{i}}\right) \\
\text { with } \boldsymbol{T}_{i}^{\text {beyond }}=\left\{j \mid \mathbf{W}_{i} \mathbf{X}_{i} \leq \mathbf{W}_{i} \mathbf{X}_{j}\right\} .
\end{gathered}
$$

In this expression, the max operation excludes negative values for $F C_{i}$. Particularly, it makes that our FC measure is bounded from below by zero, thus excluding negative foregone profitability. This accounts for the possible scenario that, in practice, firm $i$ 's actual profitability may well exceed the expected profitability (which is defined over firm observations with at least the same cost level as $i$ ). In our empirical application this last scenario applies to 29,5 percent of the firm observations, showing the need to differentiate between binding and non-binding input cost constraints. Empirically further analyzing the impact of non-binding constraints falls beyond the scope of this paper. ${ }^{9}$ Comfortingly, however, the Spearman correlation between FC with and without exclusion of negative values is 0.99 , which makes all our main conclusions robust to this choice.

\footnotetext{
${ }^{9}$ Firm size expansion when the input cost constraint is non-binding can imply substantial profitability losses. For our sample, the Mean (Standard Deviation) of FC including negative values amounts to 0.085 (0.152), which is $2.2(2.6)$ points lower (higher) than FC when the max operator is included (see Table 3). The minimum of FC with inclusion of negative foregone profitability is -0.352 , the first percentile equals to -0.248 , the 10 th percentile equals to -0.084 and the first quartile totals to -0.011 .
} 


\section{Application set-up and data construction}

The dataset is compiled by the European Central Bank and Bureau van Dijk. It augments the responses of firms that participated in the Survey on the Access to Finance of Enterprises (SAFE) with detailed balance sheet and profit \& loss information available in Orbis Europe between 2005-2015. The survey data is available from the 3rd wave of the survey (Q2-Q3 2010) until the 14th wave (Q4 2015-Q1 2016) for on average 6,500 firms in each wave, of which 90 percent are SMEs. Bureau van Dijk is not able to match every firm in SAFE with their balance sheet, but the matching is quite high (on average around $80 \%$, with variation across countries and sectors).

From this dataset, we exclude all non-manufacturing firms. Due to the computational intensity of our linear program we further limit our sample to firms operating in the five largest Euro area economies: Germany, France, Italy, Spain, and Belgium. ${ }^{10}$ This combined dataset has the advantage that it allows us to construct our new financial constraints measure (FC) from the production data included in Orbis Europe and subsequently validate its content with direct questions on financial constraints such as loan application outcomes included in the SAFE survey. ${ }^{11}$

\section{TABLES 1 and 2 HERE}

Table 1 shows how we define inputs, outputs and their prices. We include as out-

\footnotetext{
${ }^{10}$ The Netherlands is actually the fifth largest Euro area economy, but the coverage of firms in Orbis Europe is poor in the Netherlands. We replace the Netherlands by Belgium, which is the sixth largest Euro economy. Belgium.

${ }^{11}$ From 2005 onward, the sample composition of firms in Orbis Europe with non-missing production data is stable for the five included countries.
} 
put the deflated sales revenue and as inputs the number of employees in full time equivalents (FTE), deflated tangible fixed assets and deflated materials use. For the input prices, we use respectively the price of labor ${ }^{12}$, and the nace 2 -digit deflators of intermediary inputs and tangible fixed assets. ${ }^{13}$ To obtain homogeneous sets of firm observations as a basis of the FC estimation, we compare profitability only within countries in narrowly defined industry and firm size classes. We consider nace 4-digit industries (nace rev. 2 classification) and the firm size groups follow the European Commission classification of firm size categories. We thus separate micro, small, medium and large firms. In addition, we separate very small firms from small firms to deal with the large heterogeneity across small firms in terms of observables. ${ }^{14}$

We only estimate $F C_{i t}$ (i.e. foregone profitability for firm $i$ in year $t$ ) when the number of observations in a country-industry-firm size group is equal to or more than 100, resulting in 563 country-sector linear programs we ran with on average 1,093 "comparison partners" at the country-sector-firm size level. To acknowledge for the fact that inputs are not perfectly flexible, we limit the set of comparison partners for each firm to those with a similar labor cost share and capital cost share

\footnotetext{
${ }^{12}$ The price of labor is obtained by dividing labor cost by the number of employees in FTE.

${ }^{13}$ We use nace 2-digit industry-wide deflators based on EU KLEMS and Eurostat. To avoid effects of extreme outliers and extreme noise in the whole dataset, we limit the sample to observations of firms with at least five employees. We limit the sample to firms with a book year equal to 12 months. We removed the highest and lowest percentile of the level and growth rates, at the country-sector-firm size level, for the output, observed inputs, the price of labor, observed profit, observed costs, observed profitability, share of respectively materials, labor and capital in observed costs, labor productivity, capital productivity (with capital defined as tangible fixed assets) and materials productivity. We excluded labor from the cleaning on levels. We also removed clear erroneous reporting by limiting the sample to input-output observations with values over 1,000 euro and labor price with values over 10,000 euro.

${ }^{14}$ We consider five firm size groups. (1) Large firms, (2) Medium sized firms (labor in FTE lower than 250 and revenues lower than 50 million euro or total assets lower than 43 million euro), (3) Small firms (labor in FTE lower than 50 and revenues or total assets lower than 10 million euro). (4) Very small firms (small firms with labor in FTE lower than 20), (5) Micro firms (labor in FTE lower than 10 and revenues or total assets not exceeding 2 million euro).
} 
in comparison to the firm in question. In particular, only firms with labor and capital cost shares higher (lower) than 0.75 (1.25) times the respective cost shares of the firm in question are considered as potential comparison partners in our linear program discussed above.

We estimated $\Omega_{i t}$ and $F C_{i t}$ for 667,631 firm observations of 132,805 firms. ${ }^{15}$ Subsequently we dropped the top percentile of country-industry-firm size groups in terms of average cost share of latent input (to remove sectors with unrealistically high latent input levels, due to outliers that were not captured in the cleaning process), removed observations with no financial data and dropped firms with no two consecutive observations (as we use lags as independent variables in our regression analyses).

In the final sample used from now on, we have the required balance sheet information for 124,302 firms that are observed on average 4,8 times between 2005 and 2015, implying a total number of 599,778 observations. 2,676 of these firms participated on average 2.1 times in the SAFE survey, implying a total number of 5,525 observations. The panel component in the SAFE survey is thus rather weak, which limits the application of any analysis based on popular panel estimation techniques, such as (firm) fixed effects estimators.

\section{TABLE 3 HERE}

While the most popular measures of financial constraints are tailored towards listed

\footnotetext{
${ }^{15}$ We ran the linear programs for the sample of 754,167 observations of 150,040 firms, but we excluded from the further analysis all firm observations for which the linear program at the country-sector level was not able to close-to-rationalize the data using a goodness-of-fit parameter $\theta=0.9$. Cherchye et al. (2018) show in a Monte Carlo analysis that this value for the goodnessof-fit parameter ensures reliable nonparametric recovery of production function parameters and heterogeneity in productivity in settings with considerable noise. See Appendix A for some discussion.
} 
firms, our measure uses production data which is in large-scale available for both listed and (usually smaller) non-listed firms. As such, our dataset consists of both small and large firms, whereof a vast majority were never listed (99,8 percent of the sample). We consider 153,438 observations of micro firms, 315,348 observations of small firms (whereof 229,701 observations of very small firms), 108,405 observations of medium sized firms and 22,587 observations of large firms. On average, the number of employees in FTE is 57.82, ranging from 5 to 71,205. In addition, our dataset covers both starting and well-established firms, with firm age covering the range between 1 and 181. The sample is composed of 21.6 percent young firms (age lower or equal than 10), 44.2 percent mature firms (age higher than 10 and lower or equal than 25) and 34.2 percent old firms (age higher than 25).

We find that financial constraints as measured as foregone profitability is on average 0.107, meaning that we estimate firms to have a loss due to financial constraints of 10,7 percentage points of profitability, with the latter including latent input in the denominator. For half of the observations, profitability losses are estimated to exceed 6.6 percentage points. For 29,5 percent of observations, our estimates show no foregone profitability due to binding financial constraints, indicating that moving towards more costly production processes is not expected to increase profitability for these firm observations. Financial constraints seem to be quite persistent. The Spearman correlation with a one-year lag is 0.75 .

Our FC estimates as summarized in Table 4 confirm the stylized fact that financial constraints are heterogeneous across firms and that this heterogeneity is related to firm characteristics. In particular, we confirm that smaller and younger firms are more likely to face financial constraints. The average FC for micro firms is 0.118 , which is 3 percentage points higher than the average FC of medium sized and large 
firms. Young firms face on average 13.4 percent foregone profitability due to financial constraints, which is 4 percentage points higher than the FC of old firms. Comparison across countries should be considered with care due to differences in sample composition. Still, we can conclude that financial constraints are overall higher in Spain and Italy and relate in these countries more with firm size and firm age. In Italy, the connection between financial constraints and firm characteristics is most pronounced. Italian micro (small) firms face financial constraints that are 4.8 (3.7) percentage points higher than those of medium sized and large firms. Financial constraints of young firms are in Italy on average 4.2 percentage points higher than those of mature firms and 5.9 percentage points higher than the average FC of old firms. Last, results (available upon request) show that financial constraints of listed companies (1,045 firm observations) are on average 16 percent lower (i.e. 9.2 percentage points) than the financial constraints of private firms; and the financial constraints of delisted firms (131 firm observations) are on average 35 percent lower (i.e. 7.9 percentage points) than the financial constraints of private firms.

Next to the characteristics of financial constraints, we also find a robust relation between firm size and firm age on the one hand and the log of latent input on the other hand. Summary statistics show that large firms overall have higher levels of latent input. As discussed in Cherchye et al. (2018), latent input can be interpreted in terms of productivity. Our fully nonparametric estimates thus confirm the well-established positive correlation between measured productivity and firm size as discussed in for instance Haltiwanger et al. (1999); Van Biesebroeck (2005); Forlani et al. (2016).

\section{TABLE 4 HERE}




\section{Empirical validation}

In this section we investigate to what extent our new measure indeed captures the degree of financial constraints of firms by designing exercises that look at several dimensions of our measure of financial constraints. First, we use our data to show that our measure correlates in the expected way with direct indicators of financial constraints, such as loan application outcomes, and with variables that are believed to be determinants of financial constraints, such as size and age. Somewhat related to this, we also use our measure to recover the influences of macro-economic events such as the '07-'08 crisis and the sovereign debt crisis. Again this demonstrates that our measure recovers intuitive patterns.

To further validate our measure, we subsequently show that it does not pick up

other non-financial constraints (e.g. slacking product demand or regulation). We also verify that the firms that we identify as being financially constrained are indeed behaving as financially constrained firms (e.g invest less in tangible fixed assets, grant less customer credit, etc.). Finally, we show that our measure is only moderately correlated with the main existing alternative measures of financial constraints. This shows that our measure can potentially be used to address the concerns raised by Farre-Mensa and Ljungqvist (2016).

\subsection{Self-reported measures of financial constraints}

We begin by testing whether our measure correlates with five direct measures of financial constraints as reported by firms in the SAFE survey. To shed light on this, we run a logit regression to correlate the different survey based measures of financial 
constraints to our measure of financial constraints (FC), while controlling for various fixed effects:

$$
Y_{i, c, s, t}=g\left(\alpha F C_{i, c, s, t}, \beta X_{i, c, s, t-1}, \mu_{c}, \lambda_{s}, \nu_{t}, u_{i, c, s, t}\right)
$$

Where $Y_{i, c, s, t}$ represents five different survey-based measures of financial constraints. The first indicator concerns a dummy equal to 1 when a firm perceives Access to Finance to be its most pressing problem and 0 otherwise. The other four dummies concern Rejection or Discouragement, related to (a) Bank Loans, (b) Credit Lines, (c) Trade Credit, (d) Other Financing. These indicators take the value 1 when a firm was either (i) discouraged to apply for this source of external financing out of fear of rejection, (ii) when a firm applied for it but was rejected, or (iii) when a firm applied for it but had to refuse the offer because the borrowing costs were too high; and 0 when a firm applied for this source of external financing and got approved (see Table 1 for a detailed explanation of the dummies and Table 3 for

summary statistics). $F C_{i, c, s, t}$ is our new financial constraints measure. $X_{i, c, s, t-1}$ is a vector containing lagged variables that are typically believed to be determinants of financial constraints, such as the firms' financial pressure, leverage, size, and age. The model further includes country fixed effects $\mu_{c}$, nace 4-digit sector fixed effects $\lambda_{s}$ and year fixed effects $\nu_{t} \cdot u_{i, c, s, t}$ captures random noise, with subscript $i$ indicating firm, $c$ indicating country, $s$ indicating sector at the nace 4-digit level, and $t$ indicating year.

\section{TABLE 5: HERE}

The results of the logit regressions are shown in Table 5 (marginal effects reported). All five survey based indicators show a statistically significant and strong positive 
relation with our proposed FC measure. The first column sheds light on the relation between our FC measure and the probability that firms indicate that access to finance is their most pressing problem. Panel A indicates that a one standard deviation higher FC relates to a 1.4 percentage point higher probability of perceiving access to finance as the most pressing problem, which is an increase of 11.6 percent relative to the average. After the inclusion of country, sector and year fixed effects in panel $\mathrm{B}$, the estimates show a 1 percentage point increase, equaling to a 9 percent increase. Panel $\mathrm{C}$ shows that this association turns statistically insignificant when we include observed characteristics that determine financial constraints. Still, results as described in column 1 support the idea that FC measures financial constraints.

Columns 2 to 5 of Table 5 show the relation between FC and four indicators on external financing rejection or discouragement. All four indicators show a positive and significant relation with FC. These relations remain economically and statistically significant when we control for fixed effects at the country, sector and year level (Panel B) and when we include observables that relate to financial constraints (Panel $\mathrm{C})$. The results in Panel $\mathrm{C}$ indicate that our new measure captures more information on financial constraints than merely the observable characteristics.

In particular, the second column shows that our FC measure relates positively to the firm's bank loan rejection or discouragement probability. One standard deviation higher financial constraints (FC) is associated with a 6 percentage points higher rejection or discouragement probability, which is a 26.9 percent increase (relative to the unconditional mean of 23 percent). After controlling for fixed effects and control variables, we still find a 5 percentage point higher probability, equaling to a 21.7 percent increase. Similar patterns arise for rejection or discouragement related to credit lines, trade credit, and other financing. We respectively find that a one standard 
deviation higher FC corresponds to respectively a 3.2, 2.4 and 3.9 percentage point higher probability of rejection or discouragement (after controlling for fixed effects and control variables), equaling to changes over 10 percent. In Table 10 in Appendix $\mathrm{B}$, we show that these results hold when one drops the discouraged firms from the previous measures, hence only considering the rejection or approval of applications for external finance (columns 1 to 4 ), or when one adds to the previous measures also firms with no need for external financing due to sufficient internal financing available (columns 5 to 8 ). Our measure - that solely requires production data - thus recovers a substantial part of the heterogeneity in financial constraints across observations at the firm-year level.

\subsection{Determinants of financial constraints}

A second test is whether our measure of financial constraints correlates with variables that are typically believed to be determinants of financial constraints. To this end, we run regressions on $Y_{i, c, s, t}$, representing six different measures of financial constraints. $X_{i, c, s, t-1}$ is a vector containing lagged variables that are typically considered to be determinants of financial constraints, such as the firms' financial pressure (i.e. the inverse of the interest coverage ratio), leverage, size and age. As before, we include country fixed effects $\mu_{c}$, nace 4-digit sector fixed effects $\lambda_{s}$ and year fixed effects $\nu_{t}$. $u_{i, c, s, t}$ captures random noise.

$$
Y_{i, c, s, t}=g\left(\beta X_{i, c, s, t-1}, \mu_{c}, \lambda_{s}, \nu_{t}, u_{i, c, s, t}\right)
$$

In the last five columns of Table 6 we look at how the selected variables correlate with 
the five direct measures of financial constraints as reported by firms in the survey and transform model (5) into a logistic regression model. In the first column, we use OLS to study how our new measure of financial constraints relates with the selected variables. Table 6 shows that our new measure of financial constraints relates in the same way to observable (financial) characteristics that are typically believed to be determinants of financial constraints.

Our FC measure and the survey based measures show that firms that face higher financial pressure and have a higher leverage are overall more financially constrained. This is in line with what we expected since higher financial pressure implies that firms already need a large part of their earnings before interest and taxes to service their current financial debt, and thus have limited spare debt capacity. Firms with higher leverage are also more likely to face constraints on access to finance. First, a high leverage implies a low equity buffer, which could safeguard a firm from an unexpected negative shock. Second, a high leverage may also exacerbate agency conflicts between debt holder and shareholders. Further, Table 6 shows a negative relation between financial constraints and respectively firm age and firm size.

TABLE 6: HERE

\subsection{Macro-economic events}

Financial constraints might originate at the firm level (due to for instance insufficient equity or an underdeveloped business plan), but they might also originate at the macro-level. It has been shown for instance that firms report more financing obstacles

in countries where the institutional development and the development of the banking 
sector is lower (Beck et al., 2006, 2007). Another example is the occurrence of a financial or a banking crisis, which tends to amplify the financial constraints that firms face in an economy.

The global financial crisis of '07-'08 led to the insolvency of many (large) banks throughout Europe. To avoid a dramatic increase in the financial constraints of the firms in their country (i.e. to avoid a spill-over from the financial to the real sector), governments bailed out the failing banks. As these failing banks were often very large, bailing them out led to a huge increase in the outstanding government debt of many countries. In Spain and Italy, this led the financial markets to question the solvency of the sovereign. Unfortunately, as banks tend to hold significant amounts of sovereign debt, in particular of the domestic sovereign, the stress in the Spanish and Italian banking sector was not relieved after the bail-out of the failing banks as it kicked right back in once their respective sovereign became under stress. In this section we study whether our measure is able to pick up the impact of a macroeconomic event on the average level of financial constraints in an economy. The events that we consider are the financial crisis of '07-'08 and the sovereign debt crisis.

Figure 3 shows the evolution of FC over the considered time period for all countries together. The figure shows the percentage point differences with the average level in 2007 after filtering away influences from time-varying sample composition. Both the influence of the '07-'08 financial crisis and the sovereign debt crisis, which started in 2010 are well recovered by our FC measure. Both our measure and the direct survey measure on Loan Rejection or Discouragement as documented in the SAFE survey show an inverse U shape pattern of financial constraints in the period 2010- 
2015 with as peak 2013. ${ }^{16}$ The moderation of financial constraints from 2013 onward is in line with a calming of the credit markets after ECB president Mario Draghi's announcement of the "whatever-it-takes" policy to preserve the euro on July 26th, 2012 .

FIGURE 3: HERE

In Figure 4, one can see that for the FC measure, this increase of financial constraints is particularly driven by Italy and Spain (which jointly represent more than 3 quarters of our firm-level observation), consistent with the idea that the sovereign debt crisis increased financial constraints in these two countries relative to the other considered countries. $^{17}$

FIGURE 4: HERE

\subsection{Financial constraints and non-financial constraints}

One valid concern one might have about our new measure of financial constraints is whether we are not picking up other constraints firms might face (such as a drop in product demand for instance), rather than purely constraints of a financial nature.

\footnotetext{
${ }^{16}$ As the sample size for SAFE survey measures is small, we can only compare general trends over all firms. The discussed trends are robust for using the median instead of the mean.

${ }^{17}$ It should be noted that a comparison of the average levels of financial constraints across countries is difficult, as the sample composition is different. Further, our advocated measure of foregone profitability due to financial constraints relates to obstacles to finance and the influence of these obstacles on both technology choice and profitability, implying that our measure also takes into account the severity of the missed opportunities in a natural way. As such, for Germany, the higher average level of FC (compared to France for instance) may be the result of both higher levels and more heterogeneity in latent input compared to other countries. As the sample composition within a country remains quite stable, analyzing the trend within countries does not require this caution.
} 
Note though that our identification strategy tries to mitigate this by estimating the foregone profitability through comparing firms within the same country, within the same nace 4-digit industry and within the same size group. As such, we ensure that comparison firms face, for instance, the same employment protection legislation and face similar product demand. Degryse et al. (2018) show that firms operating in the same industry, in the same location and that are of comparable size, also have a similar credit demand. The differences in the firms' chosen inputs (and associated profitability) are thus likely to pertain to the differences in the degree to which firms' credit needs have been met.

This being said, we tried nevertheless to falsify the content of our measure empirically by verifying whether it correlates positively with a number of non-financial constraints that firms might face. We test whether our measure correlates positively with lack of product demand, fierce competition, too high costs of production or labor, insufficient availability of skilled employees, and too rigid regulation. The results of these tests (which are performed in a similar way as the tests in Table 5) are shown in Table 7 below. As can be seen, we find that our measure does not pick up any of these other obstacles that firms might face, which strengthens our believe that our measure is indeed able to isolate the firms' financial constraints.

TABLE 7: HERE

\subsection{The real effects of financial constraints}

In this section we aim to test whether we observe behavior of financially constrained firms that is consistent with being constrained. This may seem straightforward and 
too simplistic, but as Farre-Mensa and Ljungqvist (2016) show, this is not necessarily the case.

In contrast to Farre-Mensa and Ljungqvist (2016), we do not have an instrument at hand that exogenously changed the need for debt financing. We therefore resort to testing the impact of financial constraints on (a) growth of deflated tangible fixed assets to proxy firms' investment behavior (see Amiti and Weinstein (2018)), (b) employment growth (see Chodorow-Reich (2014)), (c) Days Sales Outstanding minus Days Payable Outstanding (DSO - DPO). The relation between financial constraints and input dynamics (a-b) is a direct consequence of input cost constraints, which we model in terms of foregone profitability. Ferrando and Mulier (2013) show that trade credit is used to manage firm growth by companies that face financial market imperfections. We expect firms that are more financially constrained to grant less credit to customers and to rely more on credit from suppliers (implying lower DSO minus DPO).

We test the real effects of financial constraints, using the following empirical model:

$$
Y_{i, c, s, t}=\alpha F C_{i, c, s, t-1}+\beta X_{i, c, s, t-1}+\gamma_{i}+\mu_{c}+\lambda_{s}+\nu_{t}+u_{i, c, s, t} .
$$

Where $Y_{i, c, s, t}$ represents real effects (a)-(c) as discussed above. $F C_{i, c, s, t-s}$ is our lagged financial constraints measure. $X_{i, c, s, t-1}$ is a vector containing the respective lag of indicator (a)-(c) and lagged variables that are typically believed to be determinants of financial constraints, such as the firms' financial pressure, leverage, size, and age. The model further includes firm fixed effects $\gamma_{i}$, country fixed effects $\mu_{c}$, nace 4-digit sector fixed effects $\lambda_{s}$ and year fixed effects $\nu_{t} \cdot u_{i, c, s, t}$ captures random noise. 
In line with the idea that our advocated financial constraints measure FC provides an accurate picture of financial constraints, Table 8 shows a negative relation between FC and investment, employment growth, and DSO minus DPO. These real effects of FC are robust for the inclusion of firm fixed effects. Economically, we find a moderate, yet non-negligible effect. A one standard deviation increase in financial constraints is estimated to decrease the log growth of tangible fixed assets by 0.05 standard deviation (0.03 when including firm FE) and decrease employment growth with 0.09 standard deviation (0.12 when firm FE are included). Further, a one standard deviation increase in financial constraints corresponds to a 0.01 standard deviation change of DSO minus DPO, with the results being robust for the inclusion of firm FE.

\section{TABLE 8: HERE}

\subsection{Comparison with existing financial constraints indices}

In this final section we compare our measure of financial constraints with three existing and widely used measures of financial constraints: the Kaplan-Zingales (KZ) index, the Whited-Wu (WW) index, and the Hadlock-Pierce (HP) index. To investigate this, we look at 1,045 firm-year observations from the 207 listed companies that are included in our dataset.

\section{TABLE 9: HERE}

We first look at simple correlations between our measure of financial constraints and the three indices, which are reported in Panel A of Table 9. As can be seen, the 
correlations are rather low. The correlation between FC and the KZ-index is less than 6 percent. The correlation with the WW-index is 23 percent and with the HP-index is 16 percent. Given that Farre-Mensa and Ljungqvist (2016) showed the inadequacy of these existing measures, this low correlation is not necessarily worrisome for our measure of financial constraints, perhaps on the contrary. Although we are aware that a low correlation does not prove the adequacy of FC as a measure of financial constraints, a high correlation would likely indicate it has the same flaws as the existing measures.

The found low correlation between FC and popularly used measures may mask offsetting high correlations with index components. To test for these potentially offsetting relations, in panel B of Table 9 we regress $\mathrm{FC}$ on the index components for each index. Columns 1 and 2 report the impact of the five components of the Kaplan-Zingales index (Tobin's Q, long term book leverage (TLTD), cash flow (CF), dividends (Div), cash holdings (Cash)). Columns 3 and 4 report the impact of the six components of the Whited-Wu index (industry sales growth (ISG), sales growth (SG), long term book leverage, cash flow, dividends, size (in terms of total assets)). Columns 5 and 6 report the impact of the three components of the Hadlock-Pierce index (size, size squared, age). Overall, we find that the respective index components explain less than 10 percent of the variation of FC. When we include fixed effects for country, sector and year, explanatory power remains below 40 percent (results available upon request are similar to the shown results without fixed effects). Only after inclusion of firm fixed effects, more than 85 percent of the variation of FC can be captured.

As can be seen, FC seems positively but insignificantly related with Tobin's Q, which is supposed to capture growth opportunities. To the same extent, FC seems to be somewhat positively related with industry sales growth and negatively with sales 
growth which are jointly supposed to capture growth opportunities in the WhitedWu model. Opportunities play a similar role in our measure, where firms will be particularly financially constrained when they operate in an environment in which investments translate easily in more profits. However, our measure does not require observable (and often inadequate) proxies to take this into account. Long term book leverage, which increases financial constraints in the Kaplan-Zingales index and the Whited-Wu index, appears to be unrelated to FC, in this sample of listed firms. Dividends seem to be negatively related to $\mathrm{FC}$, but the results hold only in the cross-section and not when dividends are considered as a dummy.

The only two components that seem to be significantly related to FC in this sample are cash flow and firm size. Financial constraints decrease with both components. In the Hadlock-Pierce model, size is capped at 4,5 billion euro and enters positively because of the included quadratic term (without the quadratic term, size enters negatively). However, in contrast to the Hadlock-Pierce model, the relation between size and financial constraints appears to be concave in our model, instead of convex in their model.

In sum, we find that the low correlations between our advocated financial constraints measure and popularly used measures go together with weak relations between our measure and sub-indicators of the alternative measures. Our index - with as distinguishing feature that it is not based on proxy variables - provides substantially different estimates of financial constraints in comparison to measures which were found to be inadequate. Stated differently, the use of a proper estimation methodology is essential for giving an adequate picture on the micro-dynamics of financial constraints. 


\section{Conclusion}

Recently, Farre-Mensa and Ljungqvist (2016) argued for the need of new financial constraint measures as none of the five most popular measures (KZ-index, WWindex, HP-index, dividend payout and credit rating) accurately measure financial constraints. In this paper, we propose to recover financial constraints from production behavior. The basis of our identification strategy is the difference between the actual observed production behavior of profit maximizing firms and the optimal production behavior derived from their comparison partners. In a fully nonparametric fashion, we detect foregone profitability as the difference between actual profitability and the profitability level we estimate to be achievable when financial constraints were less stringent. For this, we first solve a simultaneity issue that arises due to the dependency of observed input choices on usually unobserved heterogeneity in productivity.

We apply our methodology on detailed firm-year level balance sheet and profit \& loss information from Bureau van Dijk's Orbis Europe dataset for the period 20052015, which we linked with the Survey on Access to Finance of Enterprises (SAFE) as collected by the ECB at the firm level for the period 2010-2015. We cover five Euro area countries, which differ in terms of macro-events. An empirical validation of our advocated financial constraints measure shows that our indicator indeed has intriguing empirical bite. Our measure nicely picks up the financial constraint dynamics around the '07-'08 crisis and the sovereign debt crisis and relates strongly with direct survey measures of financial obstacles (e.g. loan rejections), even when we control for a wide battery of observable characteristics that are often presumed to relate to financial constraints. Further, our measure correlates as expected with well-recognized determinants of financial constraints and shows to correlate with dy- 
namics related to firm growth and use of the trade credit channel. Overall, we show that we can recover a substantial part of the heterogeneity between firm-year observations in financial constraints with the sole use of widely available production data.

Our methodology has micro-economic foundations and provides an accurate picture of financial constraints. Still, further research is needed to obtain deeper insight into the heterogeneity across firms in how they are hindered by financial obstacles. We consider this paper as a starting ground for research on financial constraints that goes beyond partial indicators and makes direct use of the optimizing production behavior of firms. For instance, by adding (e.g. dynamic) structure to the methodology or by adding financial information, estimation can be tailored to the particular situation at hand and empirical identification of financial constraints could potentially be sharpened. 


\section{References}

Ackerberg, D., Caves, K., Frazer, G., 2015. Identification properties of recent production function estimators. Econometrica 83, 2411-2451.

Afriat, S., 1972. Efficiency estimation of production functions. International Economic Review 13, 568-598.

Amiti, M., Weinstein, D., 2018. How much do bank shocks affect investment? Evidence from matched bank-firm loan data. Journal of Political Economy 126, $525-587$.

Beck, T., Demirgüç-Kunt, A., Maksimovic, V., 2005. Financial and legal constraints to growth: Does firm size matter? The Journal of Finance 60, 137-177.

Beck, T., Demirguc-Kunt, A., Laeven, L., Maksimovic, V., 2006. The determinants of financing obstacles. Journal of International Money and Finance 25, 932-952.

Beck, T., Demirguc-Kunt, A., Martinez Peria, M.S., 2007. Reaching out: Access to and use of banking services across countries. Journal of Financial Economics 85, 234-266. doi:https://doi.org/10.1016/j.jfineco.2006.07.002.

Blancard, S., Boussemart, J.P., Briec, W., Kerstens, K., 2006. Short- and long-run credit constraints in french agriculture: A directional distance function framework using expenditure-constrained profit functions. American Journal of Agricultural Economics 88, 351-364.

Carpenter, R.E., Fazzari, S.M., Petersen, B.C., 1994. Inventory investment, internalfinance fluctuations, and the business-cycle. Brookings Papers on Economic Activity , $75-138$. 
Carpenter, R.E., Fazzari, S.M., Petersen, B.C., 1998. Financing constraints and inventory investment: A comparative study with high-frequency panel data. Review of Economics and Statistics 80, 513-519.

Cherchye, L., Demuynck, T., De Rock, B., Verschelde, M., 2018. Nonparametric production analysis with unobserved heterogeneity in productivity. KU Leuven, Department of Economics Discussion Paper Series 18.11.

Chodorow-Reich, G., 2014. The employment effects of credit market disruptions: Firm-level evidence from the 2008-09 financial crisis. Quarterly Journal of Economics 129, 1-59.

Degryse, H., De Jonghe, O., Jakovljevic, S., Mulier, K., Schepens, G., 2018. Identifying credit supply shocks with bank-firm data: Methods and applications .

Diewert, W., Parkan, C., 1983. Linear programming tests of regularity conditions for production frontiers, in: Eichhorn, W., Henn, R., Neumann, K., Shephard, R. (Eds.), Quantitative Studies on Production and Prices. Physica-Verlag, Würzburg.

Färe, R., Grosskopf, S., Lee, H., 1990. A nonparametric approach to expenditureconstrained profit maximization. American Journal of Agricultural Economics 72, $574 ? 581$.

Farre-Mensa, J., Ljungqvist, A., 2016. Do measures of financial constraints measure financial constraints? The Review of Financial Studies 29, 271-308.

Fazzari, S., Hubbard, R., Petersen, B., 1988. Financing constraints and corporate investment. Brookings Papers on Economic Activity 1, 141-195.

Ferrando, A., Mulier, K., 2013. Do firms use the trade credit channel to manage growth? Journal of Banking \& Finance 37, 3035-3046. 
Forlani, E., Martin, R., Mion, G., Muûls, M., 2016. Unraveling firms: Demand, productivity and markups heterogeneity. Technical Report 293. National Bank of Belgium Working Paper Series 293.

Gandhi, A., Navarro, S., Rivers, D., 2016. On the Identification of Production Functions: How Heterogeneous is Productivity? Working Paper. University of Western Ontario, Centre for Human Capital and Productivity (CHCP).

Hadlock, C.J., Pierce, J., 2010. New evidence on measuring financial constraints: Moving beyond the KZ index. Review of Financial Studies 23(5), 1909-1940.

Haltiwanger, J., Lane, J., Spletzer, J., 1999. Productivity differences across employers: The roles of employer size, age, and human capital. American Economic Review 89, 94-98.

Hanoch, G., Rothschild, M., 1972. Testing assumptions of production theory: A nonparametric approach. Journal of Political Economy 80, 256-275.

Hoberg, G., Maksimovic, V., 2014. Redefining financial constraints: A text-based analysis. Review of Financial Studies 28, 1312-1352.

Hoshi, T., Kashyap, A., Scharfstein, D., 1991. Corporate structure, liquidity, and investment: Evidence from Japanese industrial groups. The Quarterly Journal of Economics 106(1), 33-60.

Kaplan, S.N., Zingales, L., 1997. Do financing constraints explain why investment is correlated with cash flow? Quarterly Journal of Economics 112, 169-216.

Lamont, O., Polk, C., Saa-Requejo, J., 2001. Financial constraints and stock returns. Review of Financial Studies 14(2), 529-554. 
Lee, H., Chambers, R., 1986. Expenditure-constraints and profit maximization in U.S. agriculture. American Journal of Agricultural Economics 68, 857-865.

Levinsohn, J., Petrin, A., 2003. Estimating production functions using inputs to control for unobservables. Review of Economic Studies 70, 317-341.

Marschak, J., Andrews, W., 1944. Random simultaneous equations and the theory of production. Econometrica 12, 143-205.

McFadden, D., 1978. Cost, revenue, and profit function, in: Fuss, M., McFadden, D. (Eds.), Production Economics: A Dual Approach to Theory and Applications. Amsterdam: North-Holland Publishing Co.

Olley, G.S., Pakes, A., 1996. The dynamics of productivity in the telecommunications equipment industry. Econometrica 64, 1263-1297.

Shephard, R., 1974. Indirect production functions. Verlag Anton Hain, Meisenheim Am Glad.

Van Biesebroeck, J., 2005. Firm size matters: Growth and productivity growth in African manufacturing. Economic Development and Cultural Change 53, 545-583.

Varian, H., 1984. The nonparametric approach to production analysis. Econometrica $52,579-598$.

Varian, H., 1990. Goodness-of-fit in optimizing models. Journal of Econometrics 46, $125-140$.

Whited, T.M., Wu, G., 2006. Financial constraints risk. Review of Financial Studies $19,531-559$. 
Wooldridge, J., 2009. On estimating firm-level production functions using proxy variables to control for unobservables. Economics Letters 104, 112-114. 
Figure 1: Profit maximization without heterogeneity in productivity

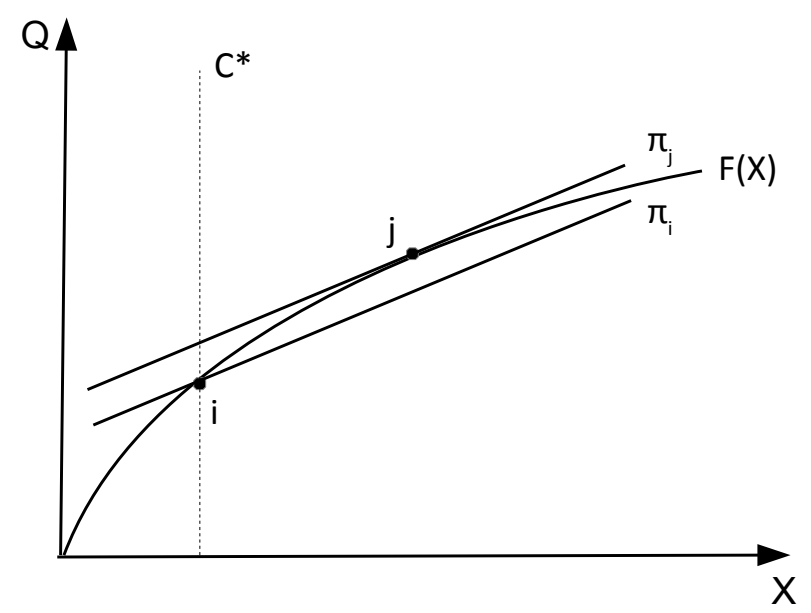

Figure 2: Production functions with heterogeneity in productivity

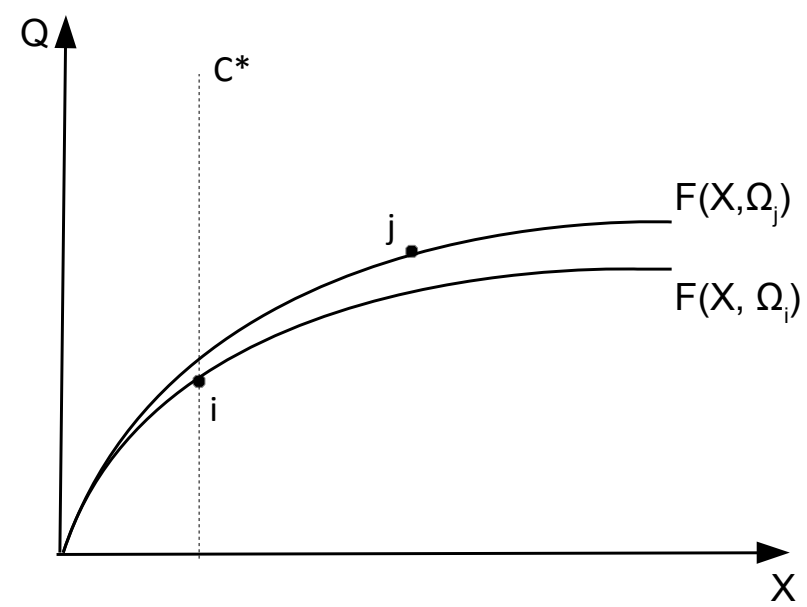


Figure 3: Financial constraints over time

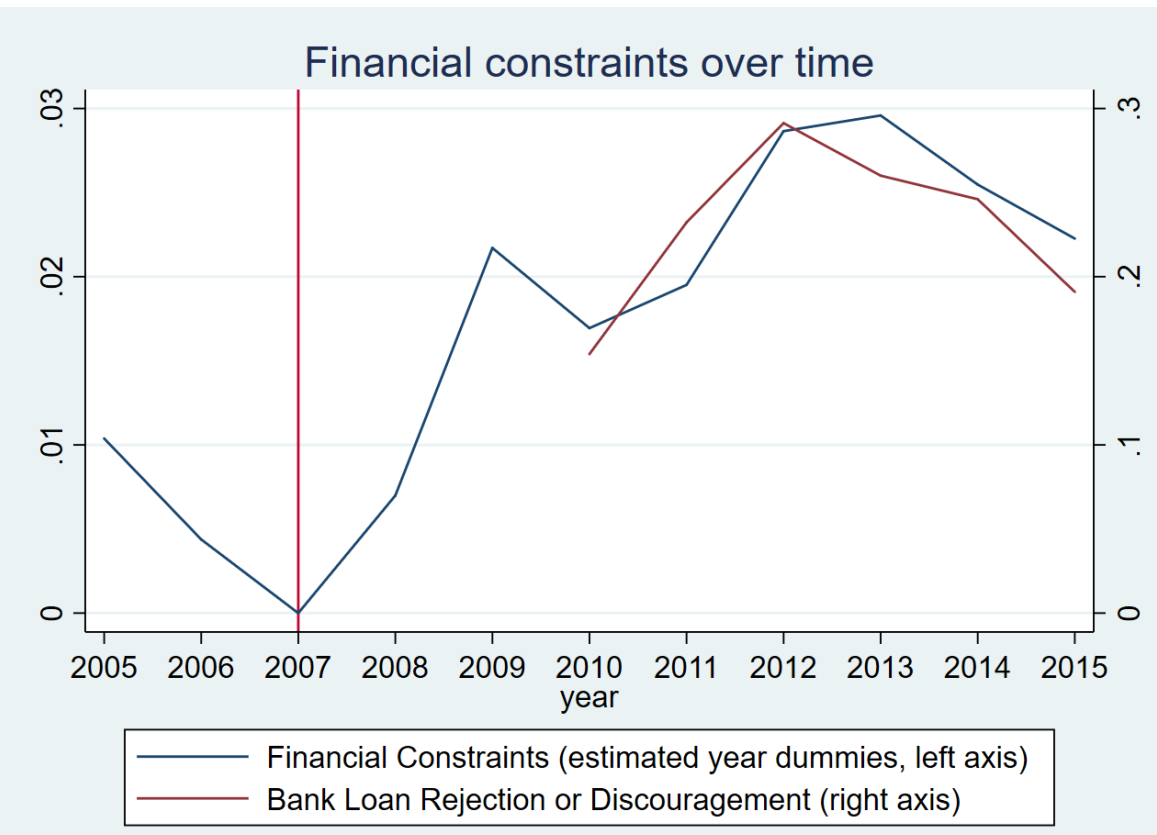


Figure 4: Financial constraints by country over time

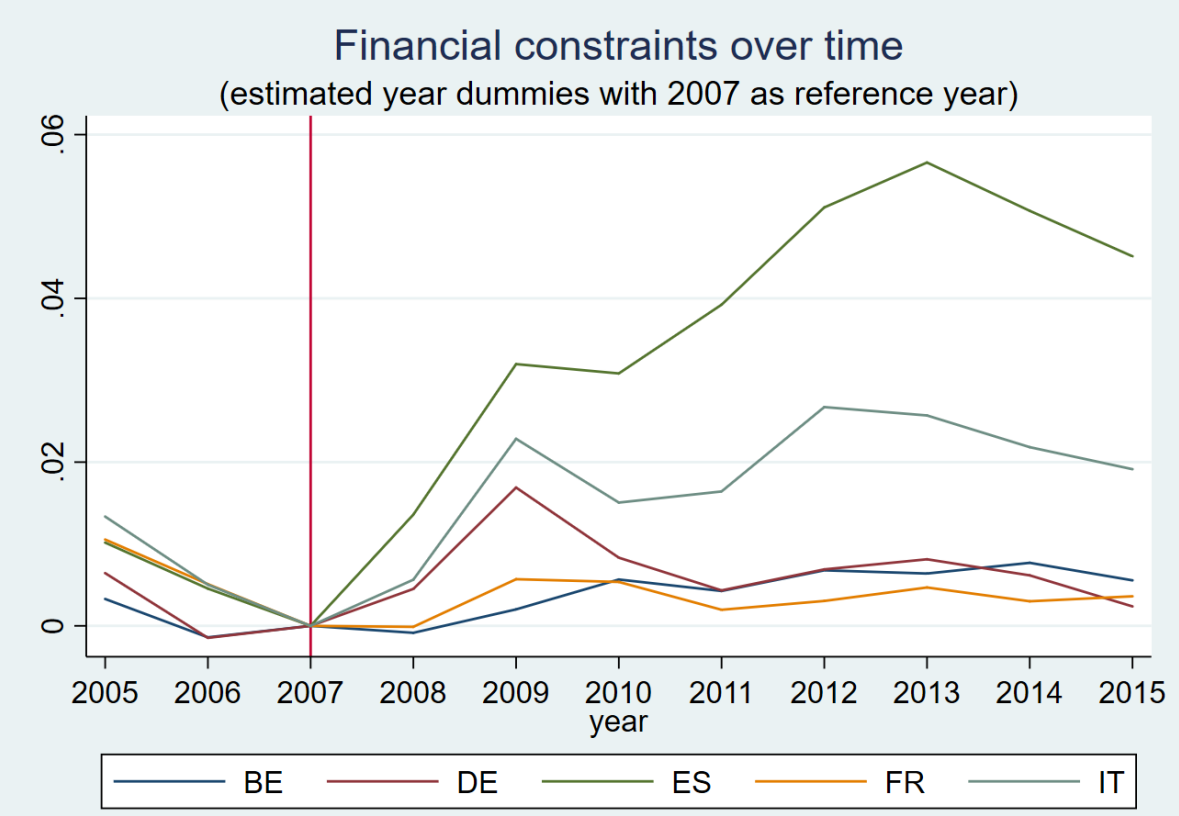




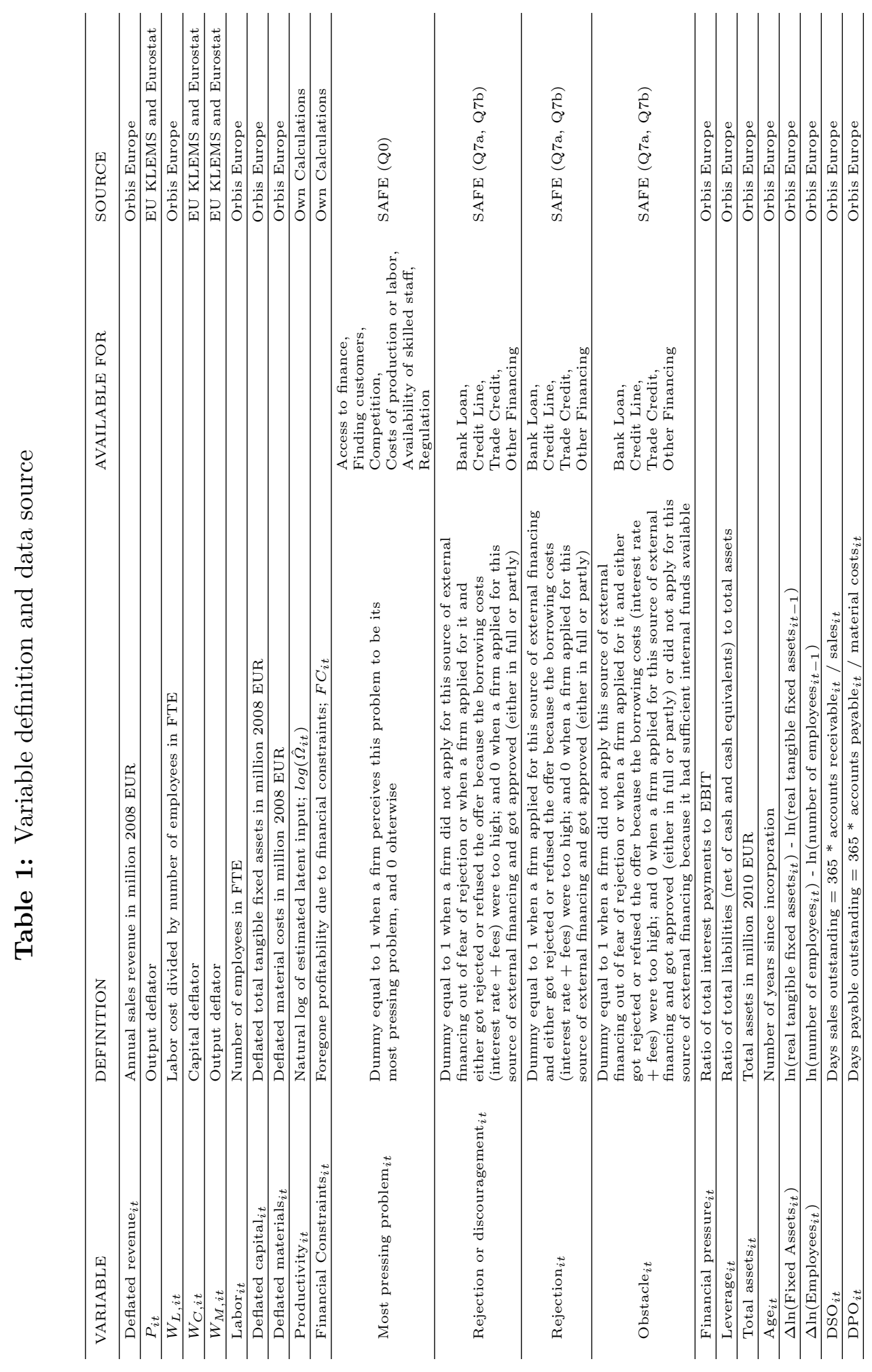


Table 2: Observations included

\begin{tabular}{lcc}
\hline Country & Firm-year observations & Number of firms \\
\hline BE & 4,604 & 845 \\
DE & 28,132 & 7,698 \\
ES & 183,757 & 37,768 \\
FR & 99,833 & 24,738 \\
IT & 283,452 & 53,253 \\
\hline Total & 599,778 & 124,302 \\
\hline
\end{tabular}


Table 3: Summary statistics

This table shows summary statistics of all variables used in this paper. Panel A shows all variables used to estimate the production function of the firms and to identify financial constraints. Panel B shows summary statistics for our new measure of financial constraints and three measures that are derived from the firm's replies to the SAFE survey. Panel C shows summary statistics of variables that are typically believed to be related to financial constraints either as determinant or as affected outcome variable.

\begin{tabular}{|c|c|c|c|c|c|}
\hline & Obs. & Mean & St.Dev. & Min. & Max. \\
\hline \multicolumn{6}{|l|}{ Panel A } \\
\hline Deflated revenue $_{i t}$ & 599,778 & 16.69 & 286.2 & 0.014 & 63,553 \\
\hline$W_{L, i t}$ & 599,778 & 0.035 & 0.013 & 0.010 & 0.715 \\
\hline$W_{C, i t}$ & 599,778 & 0.980 & 0.059 & 0.833 & 1.102 \\
\hline$W_{M, i t}$ & 599,778 & 0.980 & 0.059 & 0.833 & 1.102 \\
\hline Labor $_{i t}$ & 599,778 & 57.82 & 469.2 & 5.000 & 71,205 \\
\hline Deflated capital $_{i t}$ & 599,778 & 3.068 & 31.75 & 0.001 & 6,256 \\
\hline Deflated materials $_{i t}$ & 599,778 & 9.608 & 224.2 & 0.001 & 52,666 \\
\hline Productivity $_{i t}$ & 599,778 & 4.121 & 41.47 & 0.000 & 3,093 \\
\hline \multicolumn{6}{|l|}{ Panel B } \\
\hline \multicolumn{5}{|l|}{ Rejection or discouragement: } & 0.625 \\
\hline Bank Loan $i t$ & 1,986 & 0.230 & 0.421 & 0.000 & 1.000 \\
\hline Credit Line $i t$ & 1,499 & 0.271 & 0.445 & 0.000 & 1.000 \\
\hline Trade Credit $i t$ & 1,676 & 0.181 & 0.385 & 0.000 & 1.000 \\
\hline Other Financing $_{i t}$ & 884 & 0.204 & 0.403 & 0.000 & 1.000 \\
\hline \multicolumn{6}{|l|}{ Most pressing problem: } \\
\hline Access to finance $_{i t}$ & 5,525 & 0.121 & 0.326 & 0.000 & 1.000 \\
\hline Finding customers $i t$ & 5,525 & 0.270 & 0.444 & 0.000 & 1.000 \\
\hline Competition $_{i t}$ & 5,525 & 0.140 & 0.347 & 0.000 & 1.000 \\
\hline Costs of production or labor $i t$ & 5,525 & 0.200 & 0.400 & 0.000 & 1.000 \\
\hline Availability of skilled staff $i t$ & 5,525 & 0.093 & 0.291 & 0.000 & 1.000 \\
\hline Regulation $_{i t}$ & 5,525 & 0.083 & 0.275 & 0.000 & 1.000 \\
\hline \multicolumn{6}{|l|}{ Panel C } \\
\hline Financial Pressure $_{i t}$ & 599,778 & 0.526 & 0.661 & 0.000 & 16.77 \\
\hline Leverage $_{i t}$ & 599,778 & 0.547 & 0.307 & -0.626 & 1.248 \\
\hline Total Assets $i t$ & 599,777 & 9.139 & 31.42 & 0.092 & 1,151 \\
\hline $\operatorname{Age}_{i t}$ & 599,778 & 22.48 & 15.59 & 1.000 & 181.0 \\
\hline$\Delta \ln ($ Fixed Assets $i t)$ & 423,945 & -0.012 & 0.225 & -0.475 & 1.032 \\
\hline$\Delta \ln \left(\right.$ Employees $\left._{i t}\right)$ & 423,945 & 0.004 & 0.101 & -0.357 & 0.288 \\
\hline $\mathrm{DSO}_{i t}-\mathrm{DPO}_{i t}$ & 423,945 & -47.70 & 105.0 & -440.4 & 197.8 \\
\hline
\end{tabular}


Table 4: The FC measure and firm characteristics

This table shows the Mean and Standard Deviation (between brackets) of our new measure of financial constraints. In addition to results for the whole sample, we show the results per country, for three firm size groups and for three age groups. $* * *, * *$ and $*$ denote $\mathrm{p}<0.01, \mathrm{p}<0.05$ and $\mathrm{p}<0.1$ respectively for a two-sample t-test in which the respective group (i.e.,a column-row pair) is compared to the column one to the left at the same row (i.e., column(-1)-row pair).

\begin{tabular}{c|c|ccc|ccc}
\hline & All & Micro & Small & Medium-Large & Young & Mature & Old \\
\hline All & 0.107 & 0.118 & $0.111^{* * *}$ & $0.087^{* * *}$ & 0.134 & $0.107^{* * *}$ & $0.091^{* * *}$ \\
& $(0.125)$ & $(0.131)$ & $(0.129)$ & $(0.107)$ & $(0.145)$ & $(0.123)$ & $(0.112)$ \\
\hline BE & 0.059 & - & 0.058 & 0.060 & 0.062 & 0.063 & $0.056^{* * *}$ \\
& $(0.083)$ & & $(0.081)$ & $(0.083)$ & $(0.089)$ & $(0.081)$ & $(0.083)$ \\
DE & 0.098 & 0.107 & 0.101 & 0.098 & 0.095 & $0.103^{* * *}$ & $0.096^{* * *}$ \\
& $(0.116)$ & $(0.121)$ & $(0.119)$ & $(0.116)$ & $(0.117)$ & $(0.115)$ & $(0.116)$ \\
FR & 0.066 & 0.066 & $0.065^{*}$ & $0.067^{* * *}$ & 0.071 & $0.065^{* * *}$ & 0.064 \\
& $(0.080)$ & $(0.074)$ & $(0.077)$ & $(0.093)$ & $(0.084)$ & $(0.078)$ & $(0.081)$ \\
ES & 0.119 & 0.123 & $0.119^{* * *}$ & $0.106^{* * *}$ & 0.128 & $0.121^{* * *}$ & $0.107^{* * *}$ \\
& $(0.119)$ & $(0.120)$ & $(0.120)$ & $(0.114)$ & $(0.124)$ & $(0.119)$ & $(0.114)$ \\
IT & 0.116 & 0.132 & $0.121^{* * *}$ & $0.084^{* * *}$ & 0.154 & $0.112^{* * *}$ & $0.095^{* * *}$ \\
& $(0.140)$ & $(0.149)$ & $(0.144)$ & $(0.106)$ & $(0.162)$ & $(0.136)$ & $(0.120)$ \\
\hline
\end{tabular}




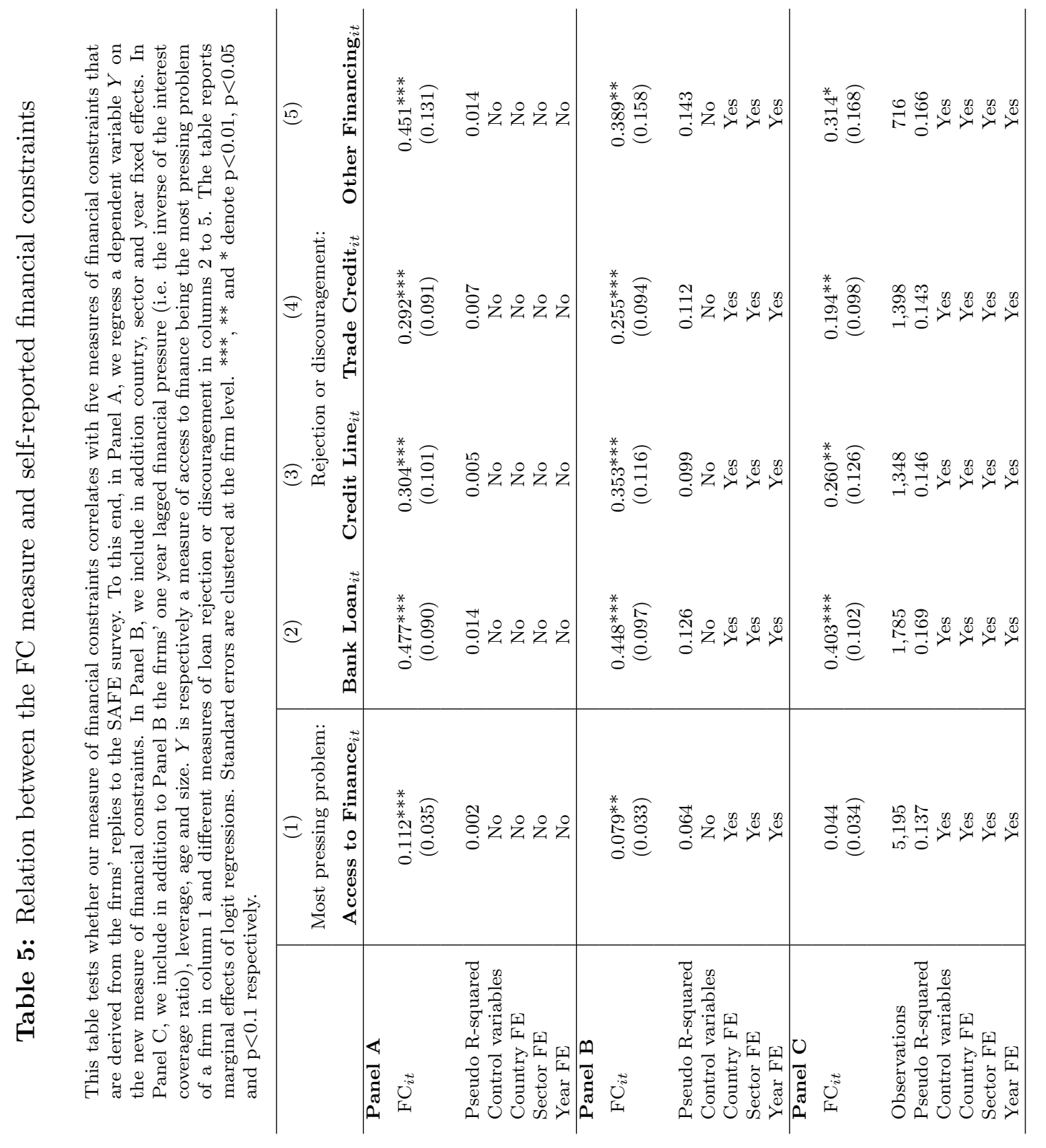




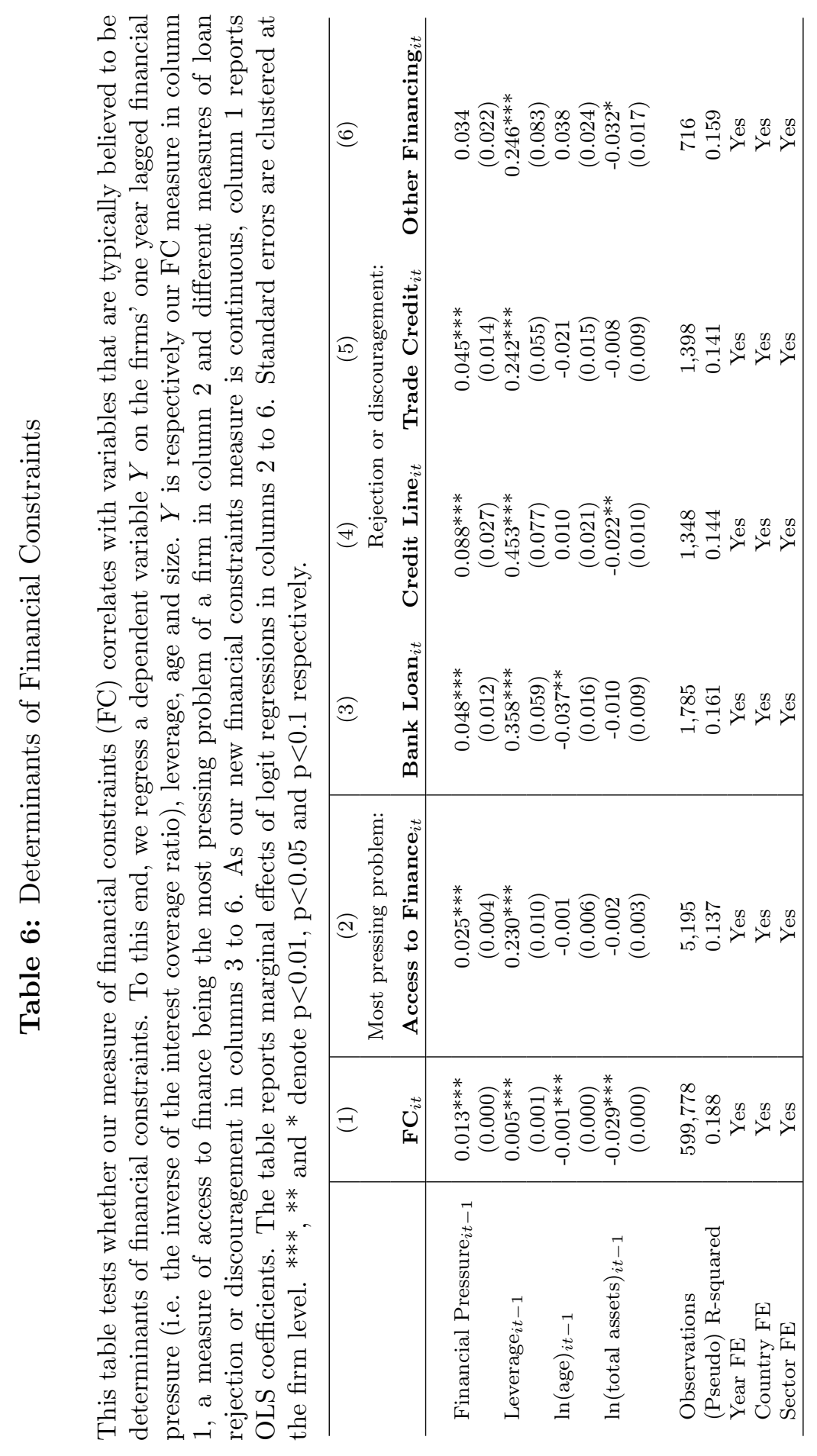




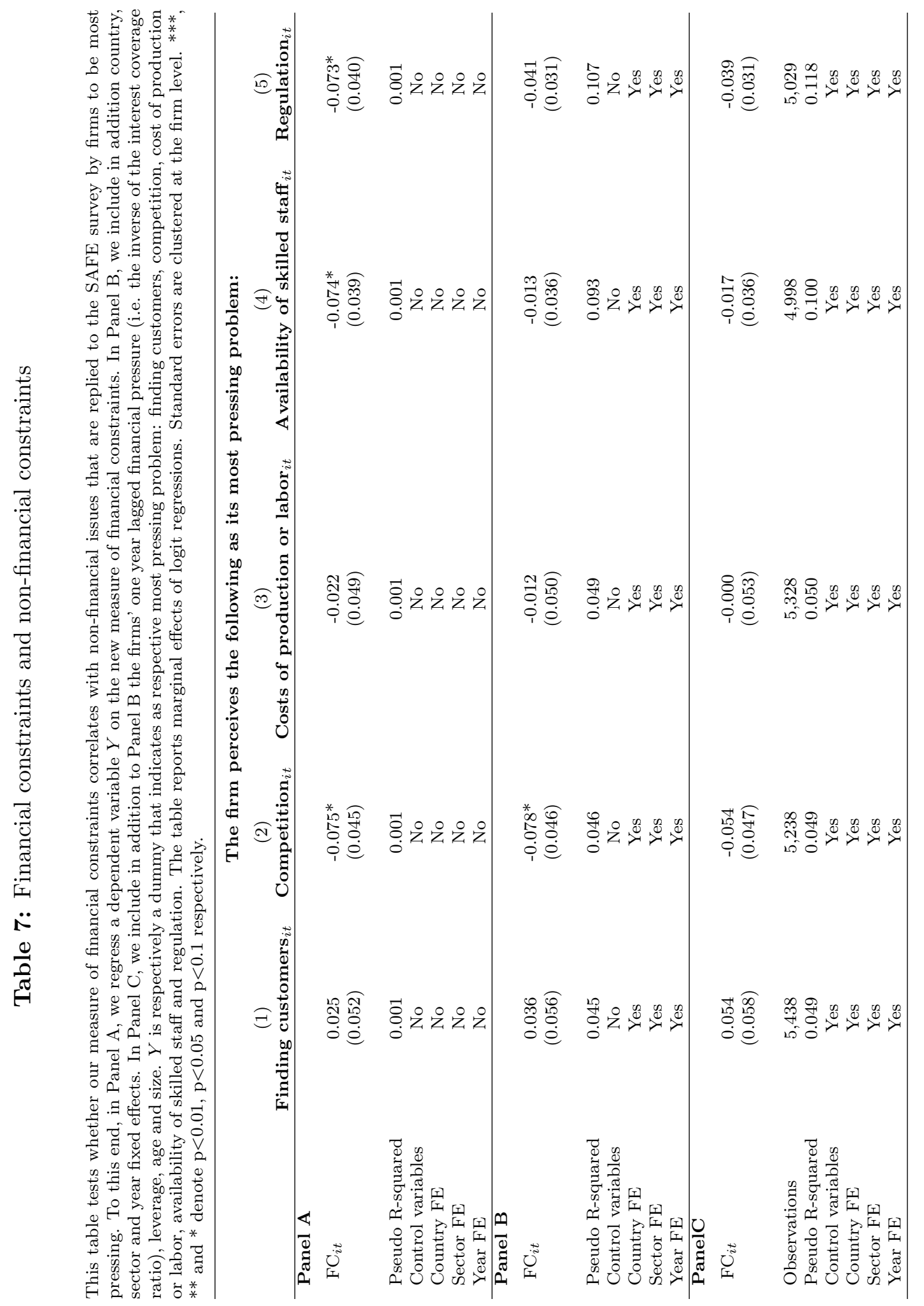




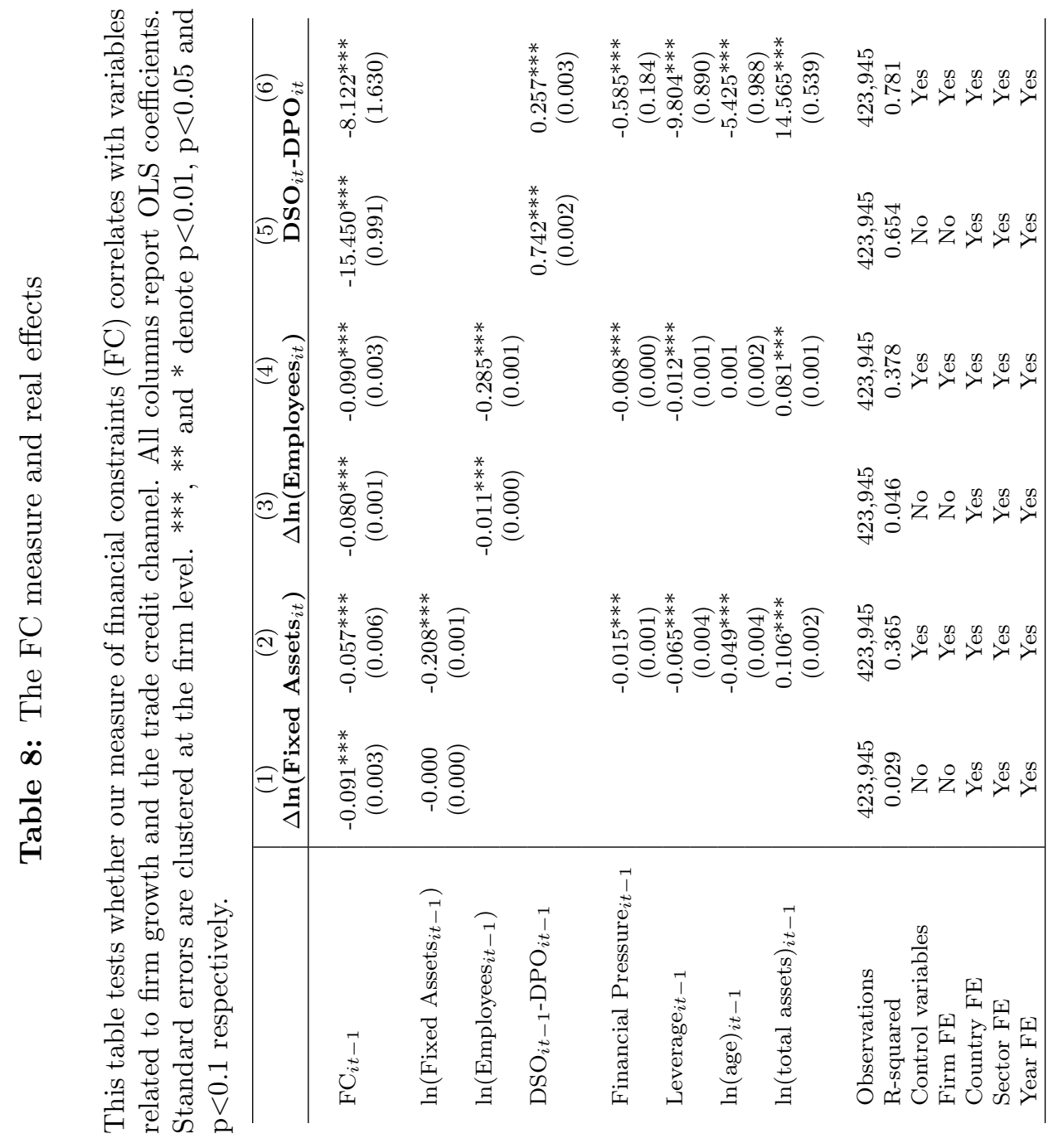


Table 9: The FC measure and widely used financial constraints indices

\begin{tabular}{|c|c|c|c|c|c|c|}
\hline Panel A & $\mathrm{FC}_{i t}$ & $\begin{array}{c}\text { Kaplan- } \\
\text { Zingales }_{i t}\end{array}$ & $\begin{array}{c}\text { Whited- } \\
\text { Wu }_{i t}\end{array}$ & & & \\
\hline Kaplan-Zingales $_{i t}$ & 0.057 & & & & & \\
\hline Whited-Wu & 0.228 & 0.057 & & & & \\
\hline Hadlock-Pierce $_{i t}$ & 0.155 & -0.123 & 0.686 & & & \\
\hline & (1) & $(2)$ & (3) & (4) & (5) & (6) \\
\hline Panel B & \multicolumn{6}{|c|}{$\mathbf{F C}_{i t}$} \\
\hline Tobin's $Q_{i t}$ & $\begin{array}{c}0.008 \\
(0.006)\end{array}$ & $\begin{array}{c}0.008 \\
(0.012)\end{array}$ & & & & \\
\hline $\operatorname{TLTD}(\mathrm{kz})_{i t}$ & $\begin{array}{c}0.019 \\
(0.012)\end{array}$ & $\begin{array}{l}-0.008 \\
(0.016)\end{array}$ & & & & \\
\hline $\mathrm{CF}(\mathrm{kz})_{i t}$ & $\begin{array}{c}-0.006^{* *} \\
(0.002)\end{array}$ & $\begin{array}{c}-0.008^{* * *} \\
(0.002)\end{array}$ & & & & \\
\hline $\operatorname{Div}(\mathrm{kz})_{i t}$ & $\begin{array}{c}-0.113^{* * *} \\
(0.036)\end{array}$ & $\begin{array}{c}-0.054 \\
(0.039)\end{array}$ & & & & \\
\hline $\operatorname{Cash}(\mathrm{kz})_{i t}$ & $\begin{array}{c}0.002 \\
(0.001)\end{array}$ & $\begin{array}{l}-0.002 \\
(0.002)\end{array}$ & & & & \\
\hline $\mathrm{ISG}_{s t}$ & & & $\begin{array}{c}0.018 \\
(0.032)\end{array}$ & $\begin{array}{c}0.020 \\
(0.018)\end{array}$ & & \\
\hline $\mathrm{SG}_{i t}$ & & & $\begin{array}{l}-0.015 \\
(0.031)\end{array}$ & $\begin{array}{c}-0.056^{* * *} \\
(0.016)\end{array}$ & & \\
\hline $\operatorname{TLTD}(\mathrm{ww})_{i t}$ & & & $\begin{array}{l}-0.011 \\
(0.030)\end{array}$ & $\begin{array}{c}0.020 \\
(0.031)\end{array}$ & & \\
\hline $\mathrm{CF}(\mathrm{ww})_{i t}$ & & & $\begin{array}{c}-0.234 * * * \\
(0.049)\end{array}$ & $\begin{array}{c}-0.234 * * * \\
(0.043)\end{array}$ & & \\
\hline $\operatorname{Div}(w w)_{i t}$ & & & $\begin{array}{c}0.003 \\
(0.008)\end{array}$ & $\begin{array}{c}-0.005 \\
(0.009)\end{array}$ & & \\
\hline Size $_{i t}$ & & & $\begin{array}{c}-0.014^{* * *} \\
(0.002)\end{array}$ & $\begin{array}{c}-0.021^{*} \\
(0.012)\end{array}$ & & \\
\hline $\operatorname{Size}(\mathrm{hp})_{i t}$ & & & & & $\begin{array}{c}0.033^{* *} \\
(0.013)\end{array}$ & $\begin{array}{l}-0.010 \\
(0.046)\end{array}$ \\
\hline $\operatorname{Size}(\mathrm{hp})_{i t}^{2}$ & & & & & $\begin{array}{c}-0.005^{* * *} \\
(0.001)\end{array}$ & $\begin{array}{l}-0.002 \\
(0.005)\end{array}$ \\
\hline $\operatorname{Age}(\mathrm{hp})_{i t}$ & & & & & $\begin{array}{c}0.000 \\
(0.000)\end{array}$ & $\begin{array}{l}-0.003 \\
(0.002)\end{array}$ \\
\hline Observations & 1,045 & 1,045 & 1,045 & 1,045 & 1,045 & 1,045 \\
\hline R-squared & 0.028 & 0.858 & 0.079 & 0.868 & 0.056 & 0.854 \\
\hline Country FE & No & Yes & No & Yes & No & Yes \\
\hline Sector FE & No & Yes & No & Yes & No & Yes \\
\hline Year FE & No & Yes & No & Yes & No & Yes \\
\hline Firm FE & No & Yes & No & Yes & No & Yes \\
\hline Index & \multicolumn{2}{|c|}{ Kaplan-Zingales } & \multicolumn{2}{|c|}{ Whited-Wu } & \multicolumn{2}{|c|}{ Hadlock-Pierce } \\
\hline
\end{tabular}




\section{Appendix A: Operationalization of the identifica- tion of productivity}

Definitions and characterization. We first define (OP)-rationalizability of the dataset $S$ under financial constraints:

Definition 1. The dataset $S=\left\{\mathbf{W}_{i}, \mathbf{X}_{i}, P_{i}, Q_{i}\right\}_{i \in N}$ is (OP)-rationalizable under financial constraints if there exist latent input levels $\Omega_{i}$ and a production function $F$ such that, for all firm observations $i \in N$,

$$
\left(\mathbf{X}_{i}, \Omega_{i}\right) \in \arg \max _{\mathbf{X}, \Omega} P_{i} Q_{i}-\mathbf{W}_{i} \mathbf{X}_{i}-\Omega_{i} \text { s.t. } \mathbf{W}_{i} \mathbf{X} \leq C_{i}
$$

From Theorem 3 of Varian (1984), we can define the following testable implications for (OP)-rationalizability of a given dataset $S .{ }^{18}$

Proposition 1. Let $S=\left\{\mathbf{W}_{i}, \mathbf{X}_{i}, P_{i}, Q_{i}\right\}_{i \in N}$. The following statements are equivalent:

(i) The dataset $S$ is (OP)-rationalizable under financial constraints;

(ii) There exist latent input numbers $\left\{\Omega_{i}\right\}_{i \in N}>0$ that satisfy, for all $i \in N$ and $j$ in $\boldsymbol{T}_{i}^{F C}=\left\{j \mid C_{i} \geq \mathbf{W}_{i} \mathbf{X}_{j}\right\}$, the inequalities

$$
P_{i} Q_{i}-\mathbf{W}_{i} \mathbf{X}_{i}-\Omega_{i} \geq P_{i} Q_{j}-\mathbf{W}_{i} \mathbf{X}_{j}-\Omega_{j}
$$

\footnotetext{
${ }^{18}$ Theorem 3 of Varian (1984) did not explicitly consider financial constraints or latent input. However, these extensions of Varian's original result are fairly straightforward and, therefore, we do not include an explicit proof.
} 
Operationalization. We can use linear programming to check our testable conditions for (OP)-rationalization under financial constraints. The linear programming problem minimizes the sum $\sum_{i}\left(\Omega_{i}\right)$ subject to the rationalizability constraints in condition (ii) of Proposition 1.

To operationalize these conditions for each firm observation $i \in N$, we need to empirically approximate the set $\boldsymbol{T}_{i}^{F C}$. Here, we use that firm $i$ 's observed cost $\mathbf{W}_{i} \mathbf{X}_{i} \leq C_{i}$. Then, we can define the set $\hat{\boldsymbol{T}}_{i}^{F C}=\left\{j \mid \mathbf{W}_{i} \mathbf{X}_{i} \geq \mathbf{W}_{i} \mathbf{X}_{j}\right\}$, which contains all firm observations $j$ with associated cost $\mathbf{W}_{i} \mathbf{X}_{j} \leq \mathbf{W}_{i} \mathbf{X}_{i}$. By construction we have that $\hat{\boldsymbol{T}}_{i}^{F C} \subseteq \boldsymbol{T}_{i}^{F C}$. Thus, we set $C_{i}$ equal to $\mathbf{W}_{i} \mathbf{X}_{i}$.

To control for heterogeneity that cannot be considered as latent input (e.g., measurement error, deviations from optimal conduct), we account for (small) deviations from "exactly" optimizing behavior in practice by using a goodness-of-fit parameter $\theta .{ }^{19}$ Basically, it weakens the original rationalizability requirement in Proposition 1 by lowering the right hand sides of the inequality constraints in condition (ii). ${ }^{20}$ Using this goodness-of-fit parameter considers "close-to" (instead of "exactly") (OP)rationalizable firm behavior.

\footnotetext{
${ }^{19}$ We may need to account for such deviations in practice as observed firm behavior may effectively fail the "exact" rationalizability condition in Proposition 1. Specifically, assume that, for some $j$ and $i, P_{i} Q_{i}-\mathbf{W}_{i} \mathbf{X}_{i}<P_{i} Q_{j}-\mathbf{W}_{i} \mathbf{X}_{j}$ and $P_{j} Q_{j}-\mathbf{W}_{j} \mathbf{X}_{j}<P_{j} Q_{i}-\mathbf{W}_{j} \mathbf{X}_{i}$. Then, we must have $\Omega_{j}>\Omega_{i}$ (because of the first inequality) and $\Omega_{i}>\Omega_{j}$ (because of the second inequality), which is infeasible. Actually, we can give this infeasibility an intuitive interpretation. The two inequalities above imply that both firm observation $j$ and firm observation $i$ turn out to be profit inefficient when compared to each other (under their respective prices). Clearly, we cannot rationalize such behavior as profit efficient with a single dimension of heterogeneity in production (i.e. a single latent input). From all this, it is clear that infeasibilities will occur only for severe violations of profit maximization (when ignoring heterogeneity in productivity).

${ }^{20}$ See, for example, Afriat (1972) and Varian (1990) for alternative goodness-of-fit measures that have been used in nonparametric production analysis.
} 
Taken together, we obtain the following linear program:

$$
\begin{gathered}
\min _{\Omega_{i} \in \mathbb{R}_{+}} \sum_{i} \Omega_{i} \\
\text { s.t. } \\
\forall i \in\{1, \ldots, N\}: P_{i} Q_{i}-\mathbf{W}_{i} \mathbf{X}_{i}-\Omega_{i} \geq \theta P_{i} Q_{j}-\left(\mathbf{W}_{i} \mathbf{X}_{j}\right) / \theta-\Omega_{j} \text { for all } j \in \hat{\boldsymbol{T}}_{i}^{F C}, \\
\text { with } \hat{\boldsymbol{T}}_{i}^{F C}=\left\{j \mid \mathbf{W}_{i} \mathbf{X}_{i} \geq \mathbf{W}_{i} \mathbf{X}_{j}\right\} .
\end{gathered}
$$

This program obtains estimates of the unobserved $\Omega_{i}$ that we will use in our practical implementation. We set $\theta=0.9$, which is the most adequate choice for datasets that may be characterized by considerable noise. See Cherchye et al. (2018) for more discussion.

\section{Appendix B: Additional tables}




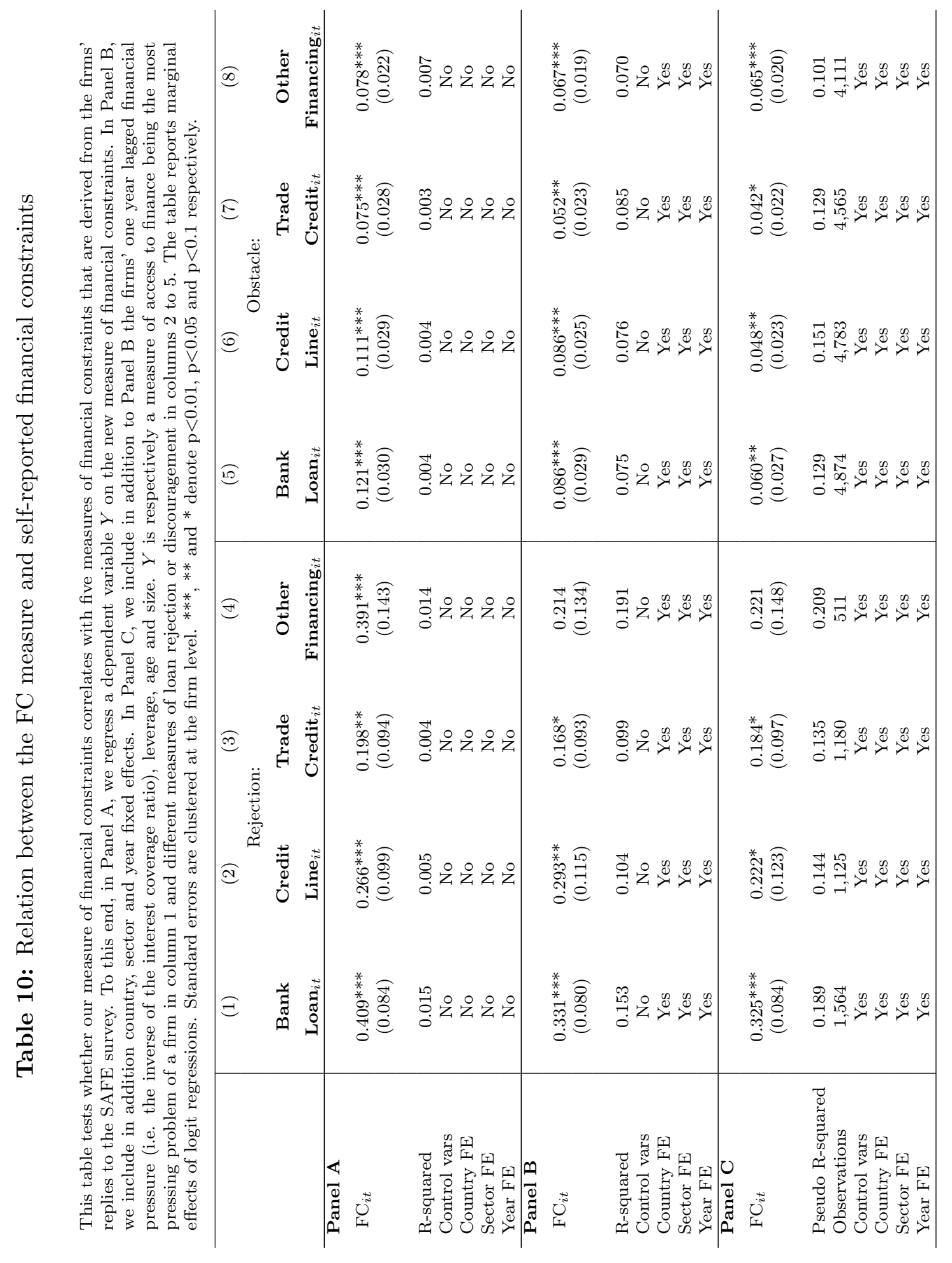

